UNIVERSIDADE FEDERAL DO RIO GRANDE DO SUL INSTITUTO DE CIÊNCIA E TECNOLOGIA DE ALIMENTOS CURSO DE ENGENHARIA DE ALIMENTOS

UTILIZAÇÃO DE FARINHA DE CASCA DE PITAIA VERMELHA (Hylocereus undatus) NA SUBSTITUIÇÃO PARCIAL DE GORDURA EM BISCOITO TIPO COOKIE

ALANA ZANCHET

PORTO ALEGRE 


\section{UTILIZAÇÃO DE FARINHA DE CASCA DE PITAIA VERMELHA (Hylocereus undatus) NA SUBSTITUIÇÃO PARCIAL DE GORDURA EM BISCOITO TIPO COOKIE}

Trabalho de conclusão de curso apresentado como requisito parcial para obtenção de título de Engenheiro de Alimentos do Instituto de Ciência e Tecnologia de Alimentos da Universidade Federal do Rio Grande do Sul.

Orientadora: Prof ${ }^{a}$. Dr ${ }^{\mathrm{a}}$. Simone Hickmann Flôres Co-Orientadora: Prof ${ }^{a}$. Dr ${ }^{\mathrm{a}}$. Roberta Cruz Silveira Thys

\section{Porto Alegre}


Trabalho de Conclusão de Curso

Utilização de farinha de casca de pitaia vermelha (Hylocereus undatus) na substituição parcial de gordura em biscoito tipo cookie

\section{ALANA ZANCHET}

Aprovada em:

COMISSÃO EXAMINADORA

Simone Hickmann Flôres (Orientadora)

Doutora em Engenharia de Alimentos

ICTA / UFRGS

Roberta Cruz Silveira Thys (Co-orientadora)

Doutora em Engenharia Química

ICTA / UFRGS

Alessandro de Oliveira Rios

Doutor em Ciência dos Alimentos

ICTA / UFRGS

\section{Renato Queiroz Assis}

Mestre em Ciência e Tecnologia de Alimentos

ICTA / UFRGS 


\section{AGRADECIMENTOS}

Gostaria de agradecer aos meus pais, que tão jovens criaram a mim e meus irmãos de forma admirável, em meio a tantas mudanças, e nada nos deixaram faltar. Ao meu pai, que sempre foi uma inspiração na minha vida, como pessoa e como profissional, por ser um exemplo de engenheiro, responsável, trabalhador incansável, dono de um coração cheio de bondade e gentileza, e de um caráter inquestionável. Obrigada pai, por ter me ajudado a escolher este curso e por ter acreditado em mim. À minha mãe, que abriu mão de alguns sonhos para estar com os filhos e acompanhar a família, e que me ensinou a base dos meus valores, sempre exigiu o melhor de mim, e me guiou nos momentos difíceis.

Agradeço aos meus irmãos, que são os meus companheiros de vida, com quem compartilhei tantos momentos, e a quem amo infinitamente. Ao meu namorado, Osvaldo Bins, que me apoiou e me inspirou, ao lado de quem eu sempre quis me tornar uma pessoa melhor. E a toda minha família, especialmente às minhas primas amigas, Renata e Érika, e a minha madrinha Eliane.

Com muita satisfação eu agradeço às minhas colegas, Luiza Helena Espina de Franco e Mariana Nunes Dutra, que se tornaram grandes amigas que eu admiro e respeito. Obrigada por terem sido minhas companheiras de curso todos esses anos. Eu fico muito feliz de ver que vencemos tantos desafios juntas, e o quanto evoluímos.

Em especial agradeço à minha Professora Orientadora, Simone Hickmann Flôres, e a minha professora Co-orientadora, Roberta Cruz Silveira Thys, que são profissionais reconhecidas e exemplares, a quem eu admiro muito e com quem eu tenho orgulho de ter trabalhado. Obrigada pela oportunidade, por toda a atenção e por todos os ensinamentos.

E, por fim, obrigada à mestranda Michele Utpott, ao doutorando Renato Queiroz e aos colegas do Laboratório de Compostos Bioativos do ICTA, que sempre estiveram disponíveis para me ajudar durante as minhas análises para este trabalho de conclusão de curso. 


\section{RESUMO}

Atualmente, existe uma preocupação alimentar em relação ao consumo exagerado de gordura presente nos alimentos, o que está associado à obesidade e diversos distúrbios de saúde. Assim, o desenvolvimento de produtos com redução ou baixo teor de gordura alcançou alta prioridade na indústria de alimentos. A casca de pitaia é uma boa fonte de pectina, antioxidantes e possui altos valores de fibras dietéticas com uma boa proporção entre as frações insolúvel e solúvel, sendo um ingrediente interessante para aplicação em biscoitos. O presente estudo teve como objetivo caracterizar a farinha produzida a partir da casca de pitaia vermelha através de análises de cor, propriedades funcionais e atividade antioxidante. Também foram avaliadas as características físico-químicas e sensoriais de biscoitos tipo cookies elaborados com substituição parcial de gordura pela farinha de casca de pitaia hidratada. Para a caracterização física, de cor e de textura foram avaliados os biscoitos com substituição de 25, 37,5 e 50\% de gordura. Para as análises de composição centesimal e de capacidade antioxidante foi avaliado o biscoito com substituição de gordura em $25 \%$, em comparação ao biscoito padrão, pois apresentou melhores propriedades físicas e de massa. A aceitabilidade foi determinada por meio de teste de aceitação sensorial de atributos com escala hedônica de nove pontos (1- desgostei muitíssimo a 9- gostei muitíssimo). A farinha apresentou baixo teor de proteínas, 4,47 $\pm 0,16 \mathrm{~g} / 100 \mathrm{~g}$, lipídios, 0,44 $\pm 0,07 \mathrm{~g} / 100 \mathrm{~g}$, e calórico, 64,07 $\pm 6,14 \mathrm{kcal} / 100 \mathrm{~g}$, e alto teor de fibra alimentar total, 61,83 $\pm 1,43 \mathrm{~g} / 100 \mathrm{~g}$. Os resultados dos cookies mostraram uma diminuição de diâmetro a partir da substituição de $37,5 \%$ da gordura, sendo que os biscoitos com redução de gordura ficaram mais macios. $\mathrm{O}$ biscoito com $25 \%$ de substituição de gordura, quando comparado ao padrão, apresentou aumento dos valores de cinzas, fibras alimentares totais e capacidade antioxidante, em aproximadamente 27, 79 e 95\%, respectivamente. Ambos os cookies apresentaram boa aceitação global com índices de aceitabilidade superiores a 70\%. Conclui-se que formulações contendo a farinha como substituto de gordura podem ser consideradas promissoras para o desenvolvimento de produtos menos calóricos e com maior teor de fibras. A farinha de casca de pitaia é interessante para novos estudos e possui potencial para ser um substituto de gordura alternativo.

Palavras-chaves: Alimentos. Substituto. Light. Fibras. Funcional. 


\begin{abstract}
Currently, there is a food concern regarding the excessive consumption of fat present in food, which is associated with obesity and various health disorders. Thus, the development of products with reduced or low fat content has reached high priority in the food industry. Pitaya peel is a good source of pectin, antioxidants and has high dietary fiber values with a good ratio between insoluble and soluble fractions, being an interesting ingredient for application in biscuits. The objective of the present study was to characterize the flour produced with red pitaia peel through analysis of color, functional properties and antioxidant activity. In addition, it evaluated the physico-chemical and sensorial characteristics of cookies made with partial replacement of fat by the hydrated flour. For the physical, color and texture characterization, the biscuits with $25,37.5$ and $50 \%$ of fat substitution were evaluated. For the analysis of chemical composition and antioxidant capacity, the biscuit with $25 \%$ of fat substitution was evaluated in comparison with the standard biscuit, since it presented better physical and dough properties. The acceptability was determined by using a hedonic scale of nine points (1- I greatly disliked it to 9- I really liked it). The flour was characterized by low protein, 4,47 \pm 0,16 g/100g, lipid, 0,44 $\pm 0,07 \mathrm{~g} / 100 \mathrm{~g}$, and caloric content, 64,07 $\pm 6,14$ $\mathrm{kcal} / 100 \mathrm{~g}$, and high levels of total dietary fiber, $61,83 \pm 1,43 \mathrm{~g} / 100 \mathrm{~g}$. The results for the cookies showed a decrease in diameter from the replacement of $37.5 \%$ of fat, and the biscuits with fat reduction became softer. The biscuit with $25 \%$ of fat replacement, when compared to the standard, showed increase of ash, total dietary fiber and antioxidant capacity, in approximately 27, 79 and 95\%, respectively. Both cookies presented good overall acceptability with acceptance rates above $70 \%$. It has been concluded that formulations containing the flour as a fat replacer can be considered promising for the development of less caloric and higher fiber products. Pitaya peel flour is interesting for further studies and has the potential to be an alternative fat replacer.
\end{abstract}

Key-words: Food. Substitute. Light. Fibers. Functional. 


\section{LISTA DE FIGURAS}

Figura 1- Biscoitos com substituição parcial de gordura através da adição de farinha de casca de pitaia vermelha: biscoito padrão (BP) e com substituição de $25 \%$ (B1); $37 \%$ (B2) e $50 \%$

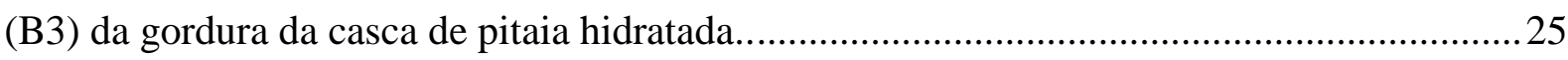

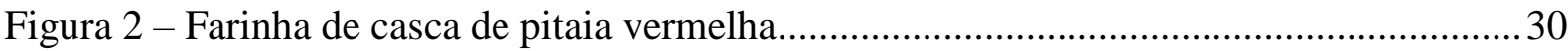

Figura 3 - Intenção de compra dos avaliadores em relação aos biscoitos padrão (BP) e com substituição de $25 \%$ (B1) da gordura por farinha de casca de pitaia hidratada........................38 


\section{LISTA DE TABELAS}

Tabela 1 - Ingredientes utilizados na produção dos cookies.

Tabela 2 - Ingredientes e composições dos biscoitos padrão (BP) e com substituição de $25 \%$ (B1), 37,5\% (B2) e 50\% (B3) da gordura por farinha de casca de pitaia hidratada

Tabela 3 - Propriedades funcionais tecnológicas da farinha de casca de pitaia

Tabela 4 - Resultados dos testes de propriedades físicas e textura do biscoito padrão (BP) e com substituição de $25 \%$ (B1), 37,5\% (B2) e 50\% (B3) da gordura por farinha de casca de pitaia hidratada 25

Tabela 5 - Resultado das análises de cor da farinha de casca de pitaia do biscoito padrão (BP) e com substituição de $25 \%$ (B1), 37,5\% (B2) e 50\% (B3) da gordura por farinha de casca de pitaia hidratada

Tabela 6 - Composição centestinal da farinha de casca de pitaia.....

Tabela 7 - Composição centestinal dos biscoitos padrão (BP) e com substituição de $25 \%$ (B1) da gordura por farinha de casca de pitaia 32

Tabela 8 - Atividade antioxidante ao Trolox das amostras de farinha de casca de pitaia e dos biscoitos padrão (BP) e com substiuição de $25 \%$ (B1) da gordura por farinha de casca de pitaia hidratada. 34

Tabela 9 - Atividade antioxidante de polpas liofilizadas tropicais, por métodos ABTS. 35

Tabela 10 - Atributos sensoriais dos biscoitos padrão (BP) e com substituição de $25 \%$ (B1) da gordura por farinha de casca de pitaia hidratada e aceitabilidade. 36 


\section{SUMÁRIO}

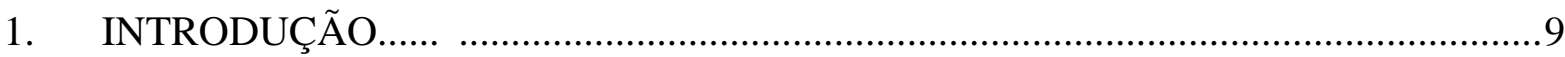

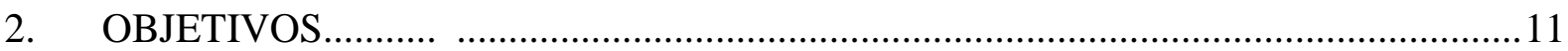

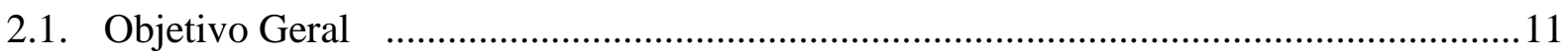

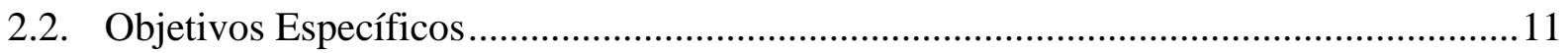

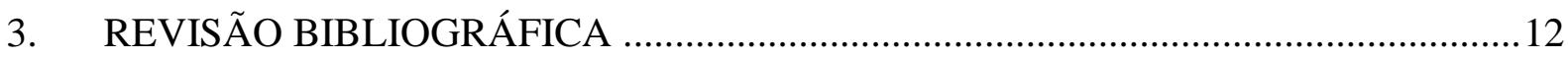

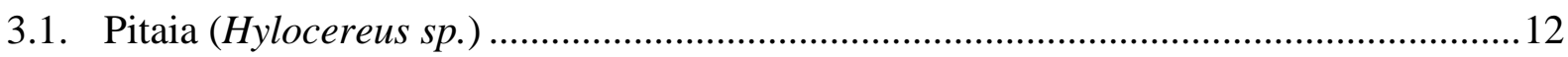

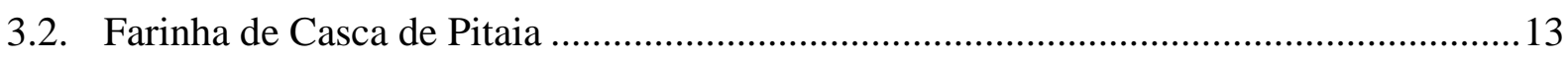

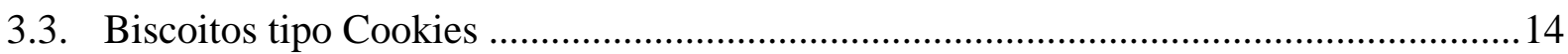

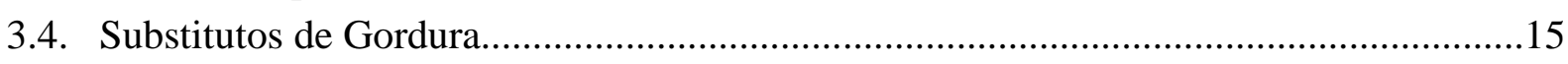

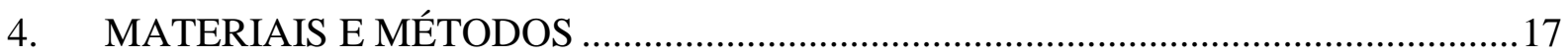

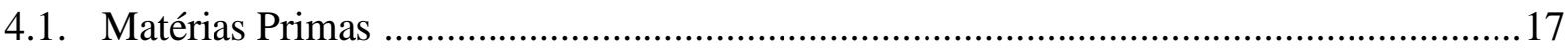

4.2. Produção da Farinha de Casca de Pitaia ...................................................................... 17

4.3. Propriedades Funcionais Tecnológicas da Farinha de Casca de Pitaia ........................... 18

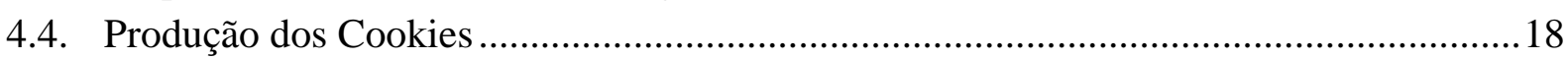

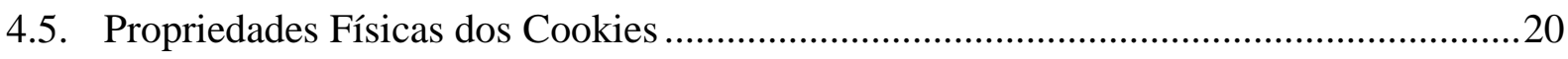

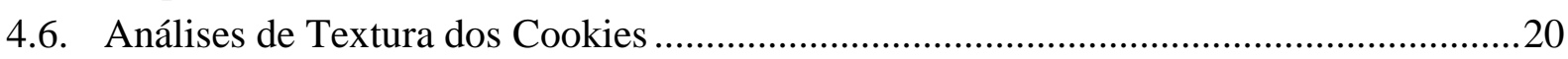

4.7. Análises de Cor da Farinha de Casca de Pitaia e dos Cookies.......................................21

4.8. Composição Centesimal da Farinha de Casca de Pitaia e dos Cookies ..........................21

4.9. Atividade Antioxidante da Farinha de Casca de Pitaia e dos Cookies ..........................21

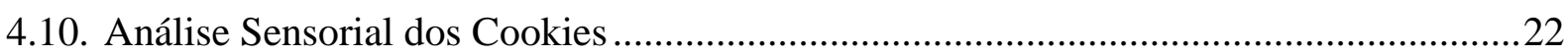

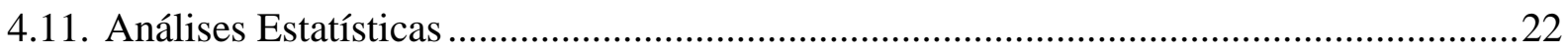

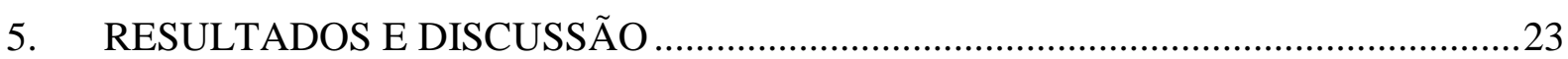

5.1. Produção da Farinha de Casca de Pitaia .......................................................................23

5.2. Propriedades Funcionais Tecnológicas da Farinha de Casca de Pitaia ............................23

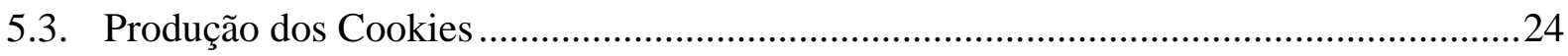

5.4. Propriedades Físicas e Textura dos Cookies ...................................................................25

5.5. Análises de Cor da Farinha de Casca de Pitaia e dos Cookies......................................29

5.6. Composição Centesimal da Farinha e dos Cookies ........................................................ 31

5.6.1. Atividade Antioxidante da Farinha de Casca de Pitaia e dos Cookies ...........................33

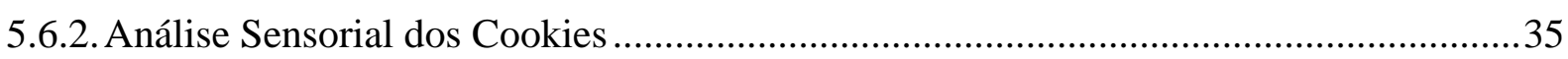

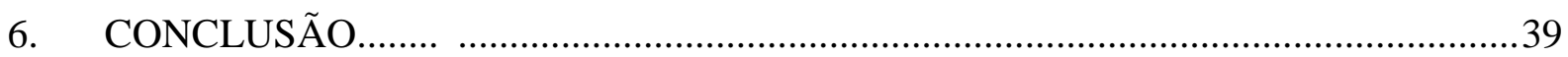

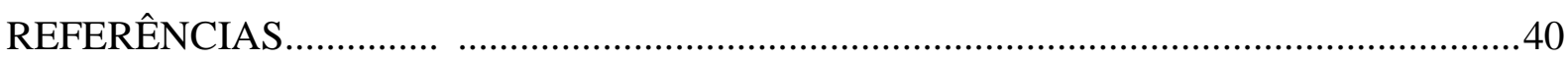

ANEXO A - Ficha utilizada para análise sensorial dos cookies .........................................45 


\section{INTRODUÇÃO}

Recentemente, a Agência Europeia de Segurança Alimentar (EFSA) recomendou que a ingestão de gordura saturada fosse a mais baixa possível, com base na relação entre a ingestão da mesma e o aumento das concentrações de colesterol (LDL) no sangue (EUROPEAN FOOD SAFETY AGENCY, 2010). O consumo de grandes quantidades de gordura e açúcar é uma preocupação alimentar atual, sendo que o consumo de gordura está associado a vários distúrbios de saúde como obesidade, câncer, colesterol elevado no sangue, e doença cardíaca coronária, enquanto a ingestão elevada de sacarose é considerada um dos fatores que causam obesidade, diabetes e doenças dentárias (ZOULIAS et al., 2000). No Brasil, o Ministério da Saúde divulgou dados que revelam o aumento da obesidade no país, onde uma em cada cinco pessoas está acima do peso. A prevalência da doença passou de $11,8 \%$ em 2006, para $18,9 \%$ em 2016, o que pode ter colaborado para o aumento da incidência de diabetes e hipertensão (BRASIL, 2017).

A crescente demanda por produtos alimentares funcionais que possuem benefícios específicos para a saúde tem sido estimulada pelos consumidores modernos, cada vez mais conscientes da relação entre a dieta e seu estado de saúde (PALZER, 2009). O desenvolvimento de produtos com baixo teor de gordura tornou-se uma alta prioridade para a indústria de alimentos, o que é um desafio especial, considerando a funcionalidade deste constituinte nos alimentos, que influencia a aparência desejável, sabor, aroma, textura e sensação na boca (LUCCA, TEPPER, 1994; PAREYT et al., 2009).

Enquanto alguns setores da indústria possuem versões alternativas de alimentos com redução de gordura conhecidas e aceitas pelos consumidores, outros, como o de panificação, geralmente estão atrasados em relação ao desenvolvimento de produtos bem sucedidos (MCEWAN; SHARP, 2000). Os substitutos de gordura são substâncias à base de carboidratos ou proteínas que podem ser usadas para imitar as propriedades funcionais e sensoriais proporcionados pela gordura e ao mesmo tempo fornecer menor valor calórico (BATH; SHELKE; HOSENEY, 1992).

Dentre os produtos de panificação, os biscoitos tipo cookies estão entre os que se destacam por possuírem a textura, sabor e aparência como os principais atributos de qualidade e a gordura é um ingrediente muito importante porque contribui com a sensação de satisfação na boca e afeta positivamente a intensidade e percepção do sabor. Muitos cookies, e especialmente aqueles do tipo macio, contém grandes quantidades de gordura (ZOULIAS et al., 2002) que são utilizadas na forma sólida ou semi sólida, predominantemente hidrogenada 
ou saturada, representando até $20 \%$ da massa de biscoito, o que implica um alto teor de ácidos graxos saturados (BALTSAVIAS et al., 1999).

Os produtos de padaria constituem pelo menos dois terços dos produtos à base de cereais, que juntamente com os cereais, contribuem com aproximadamente 15,6\% da gordura das dietas alimentares (MCEWAN; SHARP, 2000). Uma vez que o consumo de alimentos doces começa bastante cedo e é mais prevalente entre jovens e crianças, justifica-se encontrar formulações alternativas de biscoitos como uma forma estratégica de intervenção para prevenção de obesidade e outros transtornos de saúde, especialmente em crianças (FOLTZ et al., 2012; MORENO et al., 2010). Assim, existe o interesse em se produzir cookies com teor reduzido de açúcar e gordura (ZOULIAS et al., 2000).

O uso de substitutos de gordura com um perfil de ácidos graxos mais saudáveis é uma alternativa para o desenvolvimento de novas receitas de biscoitos (GIARNETTI et al., 2015). Os subprodutos da indústria de frutas e vegetais podem ter um alto valor nutricional e poderiam ser usados como ingrediente alimentar devido às suas habilidades funcionais, como gelificação e ligação à água. Os procedimentos de preparação e processamento podem levar ao descarte de até um terço do produto, o que pode ser dispendioso para o fabricante e também pode causar um impacto negativo ao meio ambiente (O'SHEA; ARENDT; GALLAGHER, 2012). A casca de pitaia vermelha é um resíduo da indústria de polpas e bebidas e possui inúmeras qualidades, sendo um produto com potencial para ser utilizado em biscoitos como substituto parcial da gordura, na forma de pó ou farinha. 


\section{OBJETIVOS}

\subsection{Objetivo Geral}

O objetivo deste trabalho foi avaliar a aplicação de farinha de casca de pitaia (hidratada) como substituto de gordura na formulação de biscoitos tipo cookies para redução da quantidade de gordura no produto e o aumento do valor nutricional.

\subsection{Objetivos Específicos}

- Produção de farinha a partir de casca de pitaia vermelha por secagem em estufa com circulação de ar forçada e trituração em moinho tipo facas;

- Determinação da composição centesimal, cor, propriedades funcionais (capacidade de retenção de água e de óleo) e atividade antioxidante da farinha de casca de pitaia;

- Utilização da farinha de casca de pitaia como substituto de gordura através da substituição de 25, 37,5 e 50\% da manteiga na formulação de biscoitos tipo cookies;

- Determinação dos parâmetros de rendimento, diâmetro, espessura, fator de expansão, volume aparente e específico, textura e cor dos biscoitos produzidos;

- Determinação da composição centesimal, atividade antioxidante e aceitação do consumidor dos biscoitos com melhores propriedades físicas e de massa. 


\section{REVISÃO BIBLIOGRÁFICA}

\subsection{Pitaia (Hylocereus sp.)}

As espécies comerciais de pitaia são principalmente duas: a de casca vermelha, Hylocereus undatus (Haw.) Briton \& Rose, e a de casca amarela, Selenicereus megalanthus (Schum. ex Vaupel) Moran. O primeiro gênero tem outras 25 espécies, algumas muito parecidas com $H$. undatus. Esta é conhecida como pitaia de casca vermelha e tem polpa branca, enquanto a amarela é de casca dessa cor, polpa branca translúcida e sementes maiores. A vermelha de polpa vermelha é a H. lemairei (Hook.) Britton \& Rose (DONADIO, 2009). É uma fruta exótica ao Brasil, que apresenta grande potencial alimentício e comercial, e que vem ganhando espaço no setor agrícola do país, com destaque para a região da Chapada do Apodí, no Ceará (NUNES, 2014).

O fruto do Hylocereus cacti, conhecido como pitaia vermelha, recentemente despertou a atenção dos produtores mundiais, não só por sua cor vermelho-púrpura e seu valor econômico como produto alimentício, mas também por sua atividade antioxidante a partir do conteúdo de betacianina (WYBRANIEC; MIZRAHI, 2002). O gênero Hylocereus consiste de cactos americanos tropicais, epífitos ou de trepadeiras, com hastes angulares e principalmente flores brancas, perfumadas, que florescem à noite. A pitaia é uma fruta de algumas cepas desta família de cactos, que é nativa das regiões da floresta tropical do México e América Central e do Sul (MIZRAHI et al., 1997). Além disso, é mencionada como uma fruta asteca popular em documentos históricos e tem uma longa linhagem no hemisfério ocidental. A pele é coberta de brácteas, ou "escamas", e por isso é chamada de "fruta do dragão". Atualmente, estão sendo cultivadas comercialmente em Taiwan, Nicarágua, Colômbia, Vietnã, Israel, Austrália e nos Estados Unidos (WU et al., 2006).

A pitaia contém muita umidade, poucos lipídios, e juntamente com outros alimentos, pode auxiliar para uma dieta equilibrada nutricionalmente. Entretanto, o que desperta a atenção para inúmeros estudos é a quantidade de compostos bioativos, principalmente pigmentos e compostos fenólicos, geralmente relacionados com a defesa do vegetal (NUNES, 2014). Esses compostos bioativos, tais como vitaminas, compostos fenólicos e pigmentos, são em sua maioria metabólitos secundários, que geralmente, estão relacionados com os sistemas de defesa das plantas contra a radiação ultravioleta ou as agressões de insetos ou patógenos, mas que nos seres humanos, em baixas concentrações, desempenham um importante papel de 
proteção como agentes antioxidantes, capazes de retardar ou inibir a oxidação de diversos substratos (HALLIWELL; GUTTERIDGE, 2015; MANACH, 2004).

\subsection{Farinha de Casca de Pitaia}

De acordo com a legislação brasileira, farinhas são os produtos obtidos de partes comestíveis de uma ou mais espécies de cereais, leguminosas, frutos, sementes, tubérculos e rizomas por moagem e ou outros processos tecnológicos considerados seguros para produção de alimentos, podendo apresentar umidade máxima de 15,0 \% (g/100 g) (ANVISA, 2005).

Aproximadamente 33\% do peso total da pitaia estão em sua casca, que muitas vezes é descartada durante o processamento, especialmente na indústria de produção de polpas e bebidas, como resíduo, ou usado como alimento para animais. Essas cascas descartadas podem causar problemas ambientais e o tratamento resultante desses resíduos tem sido muito caro para a indústria. No entanto, a casca contém enzimas, como a amilase, e pode ser usada como uma rica, natural e abundante fonte para a produção comercial de tais enzimas (AMID; MANAP, 2014).

Jamilah et al. (2011) determinou as propriedades físico-químicas de casca de pitaia descartada, para avaliar o seu potencial de recuperação de qualquer material de valor agregado. $\mathrm{O}$ teor de umidade da casca foi de aproximadamente $92,7 \%$ e esta apresentou baixo teor de sólidos solúveis totais, proteínas, cinzas e gordura. O pigmento de betacianina e a pectina obtiveram valores elevados na casca. Glicose, maltose e frutose foram detectadas, porém sacarose e galactose não. A casca também apresentou valores de fibras dietéticas insolúveis e solúveis altos, que exibiram uma boa proporção de fibra dietética insolúvel e fibra dietética solúvel. Assim, a casca de pitaia poderia ser utilizada como uma boa fonte de fibra, pectina e corante natural.

Wu et al. (2006) estudaram a pitaia vermelha em relação ao conteúdo fenólico total, atividade antioxidante e atividade antiproliferativa em células de melanoma. Em resumo, quantidades consideráveis de compostos fenólicos foram encontrados na polpa e na casca da fruta. Os resultados mostraram que a casca de pitaia vermelha pode ser uma boa fonte de antioxidantes e um agente antimelanoma. A casca de pitaia removida da fruta deve ser considerada como um produto valioso e tem potencial como ingrediente de valor agregado que pode auxiliar na prevenção de doenças crônicas. 
Portanto, converter a casca em um ingrediente facilmente manipulável, como sua forma em pó, é benéfico. A aplicação potencial deste pó de casca é muito ampla e este pode ser adicionado a vários tipos de alimentos e bebidas, como chá e bebidas à base de leite, sorvetes e iogurte, bebidas à base de frutas, pães, barras saudáveis e molhos. Devido à sua cor vermelha purpúrea, também pode ser usado como corante natural em alimentos (BAKAR et al., 2013).

\subsection{Biscoitos tipo Cookies}

De acordo com a legislação brasileira, biscoitos ou bolachas são os produtos obtidos pela mistura de farinha(s), amido(s) e ou fécula(s) com outros ingredientes, submetidos a processos de amassamento e cocção, fermentados ou não. Podem apresentar cobertura, recheio, formato e textura diversos, e devem apresentar umidade máxima de $14 \%(\mathrm{~g} / 100 \mathrm{~g})$ (ANVISA, 2005).

O "cookie", como é conhecido nos Estados Unidos, ou o "biscuit", como é conhecido no Reino Unido, é um produto pequeno, geralmente de forma plana, assado, com baixo teor de umidade, composto por três ingredientes principais: farinha, gordura e açúcar (MANLEY, 2001). Estes são biscoitos de tipo macio, cujas características de textura são principalmente fornecidas pelo seu alto teor de gordura, que fornece sabor e sensação na boca. A gordura também contribui para a aparência, palatabilidade, textura e lubrificação. A sacarose é um dos ingredientes mais importantes em biscoitos, proporcionando volume, textura e doçura (ZOULIAS et al., 2002).

A sacarose fornece doçura aos cookies, influencia as propriedades estruturais e de textura dos mesmos, e presume-se que incorpore o ar na gordura durante o processamento da massa. Além disso, em cookies, a sacarose diminui a viscosidade da massa (MAACHEREZZOUG at al., 1998). Durante o cozimento, o açúcar não dissolvido se dissolve progressivamente e, assim, contribui para o espalhamento dos biscoitos. Outros parâmetros que são influenciados pelo nível de açúcar na formulação incluem dureza, crocância, cor e volume dos cookies (HOSENEY at al., 1994). A gordura contribui com o crescimento dos biscoitos e com a aparência geral do produto, aumenta a aeração do fermento e o volume, e torna os cookies mais facilmente quebráveis (MAACHE-REZZOUG at al., 1998).

Biscoitos tipo cookies são produzidos rapidamente, porque não precisam de fermentação. O processo geral inclui a mistura dos ingredientes secos, adição de água, 
formação da massa, moldagem, assamento, resfriamento e embalagem. A maioria das formulações é feita a partir de massas que não possuem extensibilidade e elasticidade. A farinha de trigo é o principal ingrediente, mas as quantidades de gordura e açúcar adicionadas criam uma plasticidade e coesão com mínima formação de glúten. As massas de bolachas geralmente são hidratadas com quantidades relativamente baixas de água e a mistura ou amassamento é minimizado, fatores que contribuem também para a mínima formação do glúten (MANLEY, 1996; MATZ, 1992) e a consequente maciez de biscoitos deste tipo.

\subsection{Substitutos de Gordura}

Substitutos de gordura em produtos alimentares são altamente desejáveis como alternativas dietéticas para reduzir calorias, gorduras e a ingestão de colesterol (HAQUE, JI, 2003). No entanto, quando estes são utilizados, geralmente é difícil preservar as propriedades sensoriais desejáveis do produto alimentício com relação à textura, teor de umidade e sensação na boca (ZAHN et al., 2010).

Quando os ingredientes gordurosos são reduzidos nas formulações dos alimentos, eles são frequentemente substituídos por outros ingredientes necessários para cumprir seu papel funcional na manutenção das qualidades organolépticas. A lista de ingredientes oferecidos como potenciais substitutos de gordura é longa e variada, e estes podem ser divididos em três classes com base em sua composição: à base de proteínas, à base de carboidratos e à base de gordura. Cada um tem propriedades diferentes de funcionamento que fornecem tanto vantagens como limitações em aplicações específicas. Atualmente, não há nenhum substituto único que contribua com todas as qualidades sensoriais e funcionais desejadas para todos os produtos. Entretanto, uma combinação adequada de dois ou mais escolhidos com sabedoria, juntamente com a fórmula e as mudanças processuais, pode ser a melhor estratégia (LUCCA, TEPPER, 1994).

A maior parte dos substitutos de gordura são à base de carboidratos, que são polissacarídeos vegetais e incluem celulose, gomas, dextrinas, fibras, maltodextrina, amidos e polidextrose. Quando adicionados aos alimentos, encorpam e dão volume, produzindo assim uma sensação na boca semelhante à fornecida pela gordura, além de contribuírem também com a emulsão e com as propriedades estruturais. Alguns desses compostos (por exemplo, dextrinas, amidos modificados) podem ser digeridos e fornecer $4 \mathrm{kcal} / \mathrm{g}$, embora na forma hidratada o valor possa cair para 1 a $2 \mathrm{kcal} / \mathrm{g}$. Outros não são digeridos (por exemplo, 
celulose) e não têm valor calórico. Os polióis, que ajudam a absorver umidade nos alimentos, também são encontrados naturalmente em alimentos como frutas. Como eles não são totalmente absorvidos e metabolizados, eles contribuem com menos de $4 \mathrm{kcal} / \mathrm{g}$. Porém, se usados em altas concentrações, estes podem ter efeito laxativo (MATTES, 1998).

Os substitutos de gordura à base de proteínas podem ser usados de várias formas e estes contribuem com um valor calórico (energético) de 1,3 a 4 kcal/g. Quando misturados com gomas, formam géis que fornecem estrutura e funcionalidade semelhante à da gordura. As proteínas de baixo peso molecular podem atuar como gorduras para alterar a textura de um produto (por exemplo, queijo) normalmente composto de proteínas de maior peso molecular (MATTES, 1998). Os substitutos de gordura à base de gordura não são novos aos fornecedores de alimentos, embora apenas recentemente tenha sido introduzida uma formulação verdadeiramente não calórica e termoestável. Monoacilgliceróis e diacilgliceróis têm sido usados como emulsificantes e contribuem com propriedades sensoriais comparáveis às das gorduras, sendo possível conseguir a funcionalidade desejada com energia reduzida (por exemplo, $5 \mathrm{kcal} / \mathrm{g}$ versus $9 \mathrm{kcal} / \mathrm{g}$ ). Os triacilgliceróis compostos por ácidos graxos selecionados de cadeia curta e longa também podem fornecer as características sensoriais da gordura com conteúdo calórico reduzido (cerca de $5 \mathrm{kcal} / \mathrm{g}$ ) porque não são absorvidos eficientemente (WESTSTRATE; VAN HET HOF, 1995; DE GRAAF et al., 1996).

Hoje em dia espera-se que um novo substituto de gordura não só melhore as funcionalidades de processamento, mas também contribua para o benefício nutricional dos alimentos, como os produtos que contenham fibras dietéticas (LANEUVILLE et al., 2005; WARD, 1997). 


\section{MATERIAIS E MÉTODOS}

\subsection{Matérias Primas}

As pitaias foram cedidas pela empresa Agrofrutas, localizada em Novo Hamburgo / RS. Das frutas, foram retiradas as polpas, que foram embaladas a vácuo e congeladas para o aproveitamento em outros trabalhos, sendo os resíduos (cascas) embalados à vácuo e congelados para serem utilizados na produção da farinha. Os demais ingredientes, utilizados para a produção dos biscoitos tipo cookies, foram adquiridos no comércio local em Porto Alegre/RS (Tabela 1).

Tabela 1 - Ingredientes utilizados na produção dos cookies.

\begin{tabular}{lc}
\hline Ingredientes & Marca \\
\hline Farinha de trigo tipo 1 & Veneranda \\
Gotas de chocolate meio amargo & Barry Callebaut \\
Açúcar granulado & União \\
Manteiga sem sal (82\% de gorduras totais) & Elegê \\
Açúcar mascavo & Guimarães \\
Ovos tipo grande & Granja Cageri \\
Fermento químico & Royal \\
Sal & Cisne \\
Essência de amêndoas & Dr. Oetker \\
\hline
\end{tabular}

\subsection{Produção da Farinha de Casca de Pitaia}

As cascas de pitaia foram descongeladas, cortadas em pedaços pequenos (aproximadamente $1 \mathrm{~cm}^{2}$ ), pesadas, espalhadas em bandejas metálicas e colocadas em estufa de secagem com circulação de ar (New Lab, NL-80-180) sob temperatura de $60^{\circ} \mathrm{C}$, durante 9 horas. Após a secagem, foi analisado o rendimento do produto através do peso das cascas antes e depois da secagem e o teor de umidade residual segundo as normas descritas pelo Instituto Adolfo Lutz (2008), por secagem em estufa (De Leo, TLK 48) a $105{ }^{\circ} \mathrm{C}$ até peso constante. 
As cascas secas foram transformadas em farinha de baixa granulometria ( $\leq 20$ mesh) em moinho de facas (Solab Científica, SL-31). Foi analisado o rendimento do produto através do peso das cascas antes e depois da moagem.

\subsection{Propriedades Funcionais Tecnológicas da Farinha de Casca de Pitaia}

As análises de Capacidade de Retenção de Água (CRA) e de Capacidade de Retenção de Óleo (CRO) foram realizadas através de técnica utilizada por Fernández-López et al. (2009). Foram adicionados $30 \mathrm{~mL}$ de água destilada/óleo de girassol a 1 grama de farinha de casca de pitaia, homogeneizada por 1 min em vórtex (QUIMIS, 0920-A2) e deixada em temperatura ambiente $\left(\approx 25^{\circ} \mathrm{C}\right)$ por $24 \mathrm{~h}$. Após a centrifugação (Hitachi, CR21GIII, $3000 \times$ $g$ por $20 \mathrm{~min}$ ), o sobrenadante foi removido e o resíduo pesado. A capacidade de retenção de água e óleo foi expressa em gramas de água/óleo por gramas de amostra seca.

\subsection{Produção dos Cookies}

Os cookies foram produzidos no Laboratório de Panificação do Instituto de Ciência e Tecnologia de Alimentos (ICTA) da Universidade Federal do Rio Grande do Sul (UFRGS). Primeiramente, foi elaborada uma formulação para o biscoito padrão, baseada no manual de Serna-Saldivar (2012) para preparação de produtos à base de cereais. A partir da formulação do biscoito padrão foram feitas as demais formulações, que se diferenciaram apenas em relação à quantidade de gordura e à quantidade de água utilizada para hidratar a farinha de casca de pitaia adicionada em substituição à gordura. Esta quantidade de água foi primeiramente baseada nos resultados de CRA (Capacidade de Retenção de Água) da farinha, e posteriormente ajustada de acordo com as características desejadas à massa.

Os cookies foram identificados como: biscoito padrão (BP), ou seja, sem substituição de gordura e em biscoito 1 (B1), biscoito 2 (B2) e biscoito 3 (B3), produzidos com substituição de 25, 37,5 e 50\% respectivamente, da quantidade de gordura do BP, por farinha de casca de pitaia hidratada. A Tabela 2 mostra a formulação de cada biscoito. 
Tabela 2 - Ingredientes e composições dos biscoitos padrão (BP) e com substituição de 25\% (B1), 37,5\% (B2) e $50 \%$ (B3) da gordura por farinha de casca de pitaia hidratada.

\begin{tabular}{lcccc}
\hline \multirow{2}{*}{ Ingredientes } & \multicolumn{4}{c}{ Quantidades $(\mathbf{g})$} \\
\cline { 2 - 5 } & BP & B1 & B2 & B3 \\
\hline Farinha de trigo & 100 & 100 & 100 & 100 \\
Gotas de chocolate meio amargo** & 50 & 50 & 50 & 50 \\
Açúcar granulado & 40 & 40 & 40 & 40 \\
Manteiga sem sal & 28 & 21 & 17,5 & 14 \\
Açúcar mascavo & 20 & 20 & 20 & 20 \\
Ovos & 20 & 20 & 20 & 20 \\
Água & 13 & 13 & 13 & 13 \\
Fermento químico & 2,5 & 2,5 & 2,5 & 2,5 \\
Sal & 0,7 & 0,7 & 0,7 & 0,7 \\
Essência de amêndoas & 0,7 & 0,7 & 0,7 & 0,7 \\
Farinha de casca de pitaia & - & 7 & 10,5 & 14 \\
Água adicionada* & - & 15,4 & 23,1 & 30,8 \\
\hline
\end{tabular}

*Água adicionada em conjunto com a farinha de casca de pitaia, para hidratação da mesma.

**Ingrediente utilizado apenas nas formulações dos cookies utilizados para análise sensorial.

O processamento da massa do biscoito padrão ocorreu em três etapas em batedeira planetária (Arno) com batedor plano em velocidade baixa e os ingredientes foram previamente pesados em balança (Bel Engineering, Classe II). Na primeira etapa, a manteiga, o açúcar granulado, o açúcar mascavo, o sal e a essência de amêndoas foram misturados por 1 minuto. Na segunda etapa, foram adicionados os ovos e a água e misturados por mais 1 minuto. Por fim, na terceira etapa, foram adicionados a farinha de trigo e o fermento químico e misturados por mais 1 minuto. A massa pronta foi levada à refrigeração $\left(4^{\circ} \mathrm{C}\right)$ por 30 minutos para facilitar a moldagem e depois foi assada.

Da mesma forma, o processamento da massa dos demais biscoitos (B1, B2, B3) ocorreu em três etapas, se diferenciando apenas pela hidratação prévia da farinha de casca de pitaia por 30 minutos, que foi adicionada à etapa 1. Optou-se por adicionar as gotas de chocolate meio amargo apenas aos biscoitos produzidos para a análise sensorial, para que este ingrediente não interferisse nos resultados das demais análises, uma vez que não compõe todas as partes do biscoito uniformemente. 
As massas foram pesadas em pequenas porções de 24 gramas, moldadas manualmente em formato circular, colocadas em fôrmas retangulares de inox previamente untadas e achatadas manualmente para adquirirem o formado desejado de cookie. Os biscoitos foram assados em forno turbo elétrico (Tedesco, FTT $150 \mathrm{E}$ ) a $160^{\circ} \mathrm{C}$ por 8 minutos, com préaquecimento de 15 minutos a $160^{\circ} \mathrm{C}$. Depois de assados, os biscoitos foram resfriados em temperatura ambiente por 1 hora e analisados.

\subsection{Propriedades Físicas dos Cookies}

As análises físicas foram feitas no Laboratório de Panificação do Instituto de Ciência e Tecnologia de Alimentos (ICTA) da Universidade Federal do Rio Grande do Sul (UFRGS), de acordo com os procedimentos descritos no método 10-50D da American Association of Cereal Chemists - AACC (AACC, 1995).

Foram utilizadas cinco unidades de uma mesma fornada para cada tipo de biscoito. As análises físicas determinaram o peso, diâmetro e espessura, avaliados antes e depois da cocção. A pesagem foi realizada em balança (Bel Engineering, Classe II) e o diâmetro e espessura foram medidos com paquímetro (Maub). O rendimento foi calculado a partir dos pesos antes e depois da cocção. O cálculo do fator de expansão foi feito pela razão entre o diâmetro e a espessura dos biscoitos. O volume aparente foi determinado pelo método de deslocamento de sementes de painço (DE MORAES et. al, 2010). O volume específico foi determinado pela razão entre o volume aparente e o peso dos biscoitos, expresso em mL.g ${ }^{-1}$.

\subsection{Análises de Textura dos Cookies}

A textura dos biscoitos foi medida com o uso de um texturômetro TA.XT. plus (Stable Micro Systems, UK), através de sonda cilíndrica de alumínio com $2 \mathrm{~mm}$ de diâmetro, que penetrou $10 \mathrm{~mm}$ com velocidade de $1 \mathrm{~mm} \cdot \mathrm{s}^{-1}$. A resistência à penetração, ou dureza, foi medida através da área total abaixo da força vs. a curva de tempo, que corresponde ao trabalho de penetração (N.s). As medidas foram feitas em triplicata. 
4.7 Análises de Cor da Farinha de Casca de Pitaia e dos Cookies

As análises de cor dos cookies foram realizadas instrumentalmente através de colorímetro Minolta CR-400 (Japão). Os resultados foram expressos em termos de L*, luminosidade (valores de 0 a 100\%), a*, vermelho ao verde (60 a -60, respectivamente) e $b^{*}$, amarelo ao azul (60 a -60 , respectivamente), de acordo com o sistema de cores CIELab. As medidas foram feitas com a utilização do branco padrão, dentro das mesmas condições de luz e temperatura, em triplicata para cada tipo de biscoito.

\subsection{Composição Centesimal da Farinha de Casca de Pitaia e dos Cookies}

As análises foram realizadas no Laboratório de Compostos Bioativos do Instituto de Ciência e Tecnologia de Alimentos (ICTA) da Universidade Federal do Rio Grande do Sul (UFRGS), seguindo a metodologia descrita pela Association of Official Analytical Chemists (AOAC,1995) (HORWITZ, 2005) para umidade, proteína (fator de conversão de 6,25), cinzas, lipídios e fibras alimentares. O teor de carboidratos disponíveis foi calculado por diferença: 100 - (umidade + cinzas + fibras + proteínas + lipídios). O valor calórico foi determinado por cálculo, em kcal, segundo a Equação (1).

Valor calórico $(\mathrm{kcal})=(4 x$ proteínas $+4 x$ carboidratos $+9 x$ lipídeos $)$

Equação (1)

\subsection{Atividade Antioxidante da Farinha de Casca de Pitaia e dos Cookies}

As análises de atividade antioxidante da farinha de casca de pitaia e dos cookies (padrão e com substituição de gordura em 25\%) foram realizadas no Laboratório de Compostos Bioativos do Instituto de Ciência e Tecnologia de Alimentos (ICTA) da Universidade Federal do Rio Grande do Sul (UFRGS), seguindo a metodologia descrita por Re et al. (1999) e Rufino et al. (2007) para dosagem de atividade antioxidante total por método ABTS. Os resultados do ensaio foram expressos em relação ao Trolox em termos de TEAC (capacidade antioxidante equivalente de Trolox). 


\subsection{Análise Sensorial dos Cookies}

A análise sensorial foi realizada para o biscoito padrão e para o biscoito com substituição de gordura em 25\% (ambas as formulações contendo gotas de chocolate). Um painel não treinado de 50 pessoas, 18 homens e 32 mulheres, com idades entre 19 e 55 anos, avaliaram os cookies em termos de aparência, cor, odor, textura, sabor, sabor residual e aceitação global. As amostras, codificadas com três dígitos, foram oferecidas aos avaliadores de forma monádica e aleatória em cabines individuais, sob iluminação branca. A escala de nove pontos foi utilizada para avaliação, onde 1 correspondeu a "desgostei muitíssimo" e 9 a “gostei muitíssimo". A intenção de compra também foi avaliada. Para o cálculo do Índice de Aceitabilidade (\%) de cada atributo, foi utilizada a equação (2), sendo consideradas bem aceitas as amostras com percentual de aceitação superior a 70\% (MEILGAARD et al., 2007).

$I A(\%)=($ Média de aceitação/9) $\times 100$

Equação (2)

\subsection{Análise Estatística}

Os resultados foram submetidos à análise de variância (ANOVA) e as médias foram comparadas através do teste de Tukey com 95\% de significância. As análises foram realizadas por meio do software Statistica 12.0. 


\section{RESULTADOS E DISCUSSÃO}

\subsection{Produção da Farinha de Casca de Pitaia}

O rendimento da secagem da casca de pitaia foi de $8,4 \%$. Tal valor se justifica pelo alto teor de umidade da casca in natura, que pode variar de 89,46 a 92,65\% (ABREU et al., 2012; JAMILAH et al., 2011). O resultado da análise de umidade das cascas secas foi de $9,72 \%$, valor considerado adequado para a produção de farinha. O rendimento da moagem das cascas de pitaia foi de $94,4 \%$, sendo que as perdas ocorreram principalmente no moinho de facas.

5.2 Propriedades Funcionais Tecnológicas da Farinha de Casca de Pitaia

A Tabela 3 mostra os resultados da análise de Capacidade de Retenção de Água (CRA) e Capacidade de Retenção de Óleo (CRO) da farinha de casca de pitaia.

Tabela 3 - Propriedades funcionais tecnológicas da farinha de casca de pitaia.

\begin{tabular}{lc}
\hline \multirow{2}{*}{ Parâmetro } & Resultados \\
\cline { 2 - 2 } & Farinha de Casca de Pitaia \\
\hline CRA (g de água / g de amostra seca) & $8,16 \pm 0,37$ \\
CRO (g de óleo / g de amostra seca) & $2,03 \pm 0,28$ \\
\hline CRA: Capacidade de retenção de água. CRO: Capacidade de retenção de óleo. Média \pm desvio padrão.
\end{tabular}

A CRA está diretamente relacionada com o teor de fibras do alimento porque mede a quantidade máxima de água absorvida que é retida pela mesma. Além disso, a CRA é uma propriedade importante no preparo de produtos de panificação, uma vez que é necessária uma boa retenção de água para obter um produto macio e úmido por mais tempo (GIUNTINI et al., 2003).

Souza et al. (2008) estudaram a composição centesimal e as propriedades funcionais tecnológicas da farinha da casca do maracujá e encontraram valor de CRA de 4,8 $\pm 0,18 \mathrm{~g}$ de água/g de amostra seca, maior do que aqueles encontrados para as outras fontes de fibras, como farelo da casca de milho $(2,32 \pm 0,2 \mathrm{~g}$ de água/g de amostra seca), farelo da casca de 
trigo $(2,48 \pm 0,27 \mathrm{~g}$ de água/g de amostra seca) e farelo da casca de soja $(1,27 \pm 0,12 \mathrm{~g}$ de água/g de amostra seca). O resultado obtido deste parâmetro para a farinha de casca de pitaia foi maior que todas as fontes estudadas por Souza et al. (2008). Esse fator propicia o preparo de produtos panificados com boa retenção de água, mais macios e úmidos por mais tempo.

A CRO pode influenciar a ordem de adição dos ingredientes secos na mistura durante o processamento de alimentos e altos valores são desejáveis em produtos cárneos e produtos emulsionados para uma melhor sensação na boca (BOBBIO, 1995). Assim, a farinha de casca de pitaia pode ter contribuído positivamente com a textura dos biscoitos devido à este parâmetro.

\subsection{Produção dos Cookies}

A água adicionada para a hidratação da farinha de casca de pitaia, quando utilizada de acordo com o valor total de CRA (8,16 g de água/g de amostra), causou hidratação excessiva na massa teste. Assim, a quantidade de água foi reduzida para apenas hidratar superficialmente toda a farinha (2,2 $\mathrm{g}$ de água/g de amostra). Inicialmente foi planejado fazer a substituição gradual da gordura do biscoito padrão nas quantidades de 25\%, 50\%, $75 \%$ e $100 \%$, entretanto, no momento da produção, foi verificado que, quanto maior a substituição da gordura pela farinha de casca de pitaia (hidratada), maior foi a dificuldade de manipulação e moldagem da massa, que adquiriu características negativas de emoliência e pegajosidade com um valor de $50 \%$ da substituição da gordura. Desta forma, não foi possível realizar substituições de $75 \%$ e $100 \%$, sendo portanto incluída no desenvolvimento do produto uma formulação extra com substituição da gordura em 37,5\%. Assim, a substituição gradual da gordura do biscoito padrão foi feita nas quantidades de $25 \%$ (biscoito B1), 37,5\% (biscoito B2) e $50 \%$ (biscoito B3).

A formulação do biscoito padrão apresentou a característica de textura de massa ideal para a manipulação e moldagem no processamento, sendo esta firme, lisa e não aderente às mãos e aos utensílios. A massa do biscoito com substituição de gordura em $25 \%$ foi a que apresentou esta característica mais semelhante à massa do biscoito padrão, seguida pela do biscoito com substituição de gordura em 37,5\%. A massa do biscoito com substituição de gordura em $50 \%$ gerou dificuldades para manipulação e moldagem, por aderir às mãos e aos utensílios. Na Figura 1 podem ser observadas as imagens dos biscoitos prontos. 
Figura 1- Biscoitos com substituição parcial de gordura através da adição de farinha de casca de pitaia vermelha: biscoito padrão (BP) e com substituição de $25 \%$ (B1); $37 \%$ (B2) e 50\% (B3) da gordura da casca de pitaia hidratada.
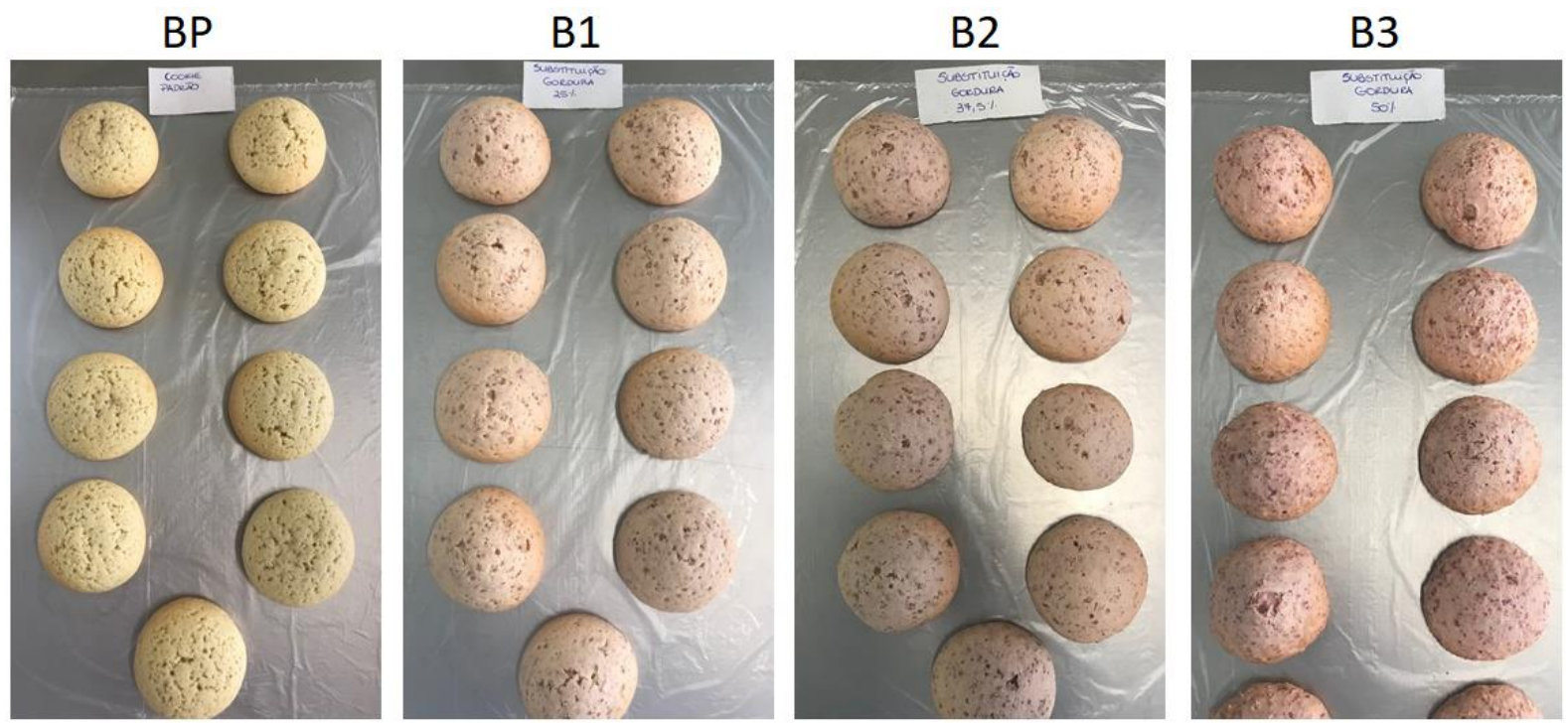

5.4 Propriedades Físicas e Textura dos Cookies

A Tabela 4 apresenta os efeitos da substituição de gordura nos cookies através dos resultados da caracterização física e de textura dos mesmos.

Tabela 4 - Resultados dos testes de propriedades físicas e textura do biscoito padrão (BP) e com substituição de $25 \%$ (B1), 37,5\% (B2) e 50\% (B3) da gordura por farinha de casca de pitaia hidratada.

\begin{tabular}{lcccc}
\hline Parâmetros & \multicolumn{4}{c}{ Resultados } \\
\cline { 2 - 5 } & $\mathbf{B P}$ & $\mathbf{B 1}$ & $\mathbf{B 2}$ & $\mathbf{B 3}$ \\
\hline Rendimento (\%) & $91,72 \pm 0,01^{\mathrm{a}}$ & $89,62 \pm 0,01^{\mathrm{b}}$ & $89,66 \pm 0,01^{\mathrm{b}}$ & $87,83 \pm 0,01^{\mathrm{c}}$ \\
Aumento de Diâmetro & $1,07 \pm 0,01^{\mathrm{a}}$ & $1,05 \pm 0,05^{\mathrm{a}}$ & $0,69 \pm 0,05^{\mathrm{b}}$ & $0,59 \pm 0,05^{\mathrm{b}}$ \\
$(\mathrm{cm})$ & & & \\
Aumento de Espessura & $0,60 \pm 0,07^{\mathrm{b}}$ & $0,81 \pm 0,02^{\mathrm{a}}$ & $0,84 \pm 0,03^{\mathrm{a}}$ & $0,87 \pm 0,04^{\mathrm{a}}$ \\
$(\mathrm{cm})$ & & & \\
Fator de Expansão & $2,45 \pm 0,06^{\mathrm{a}}$ & $2,29 \pm 0,04^{\mathrm{ab}}$ & $2,16 \pm 0,07^{\mathrm{b}}$ & $2,12 \pm 0,11^{\mathrm{b}}$ \\
Volume Específico & $1,80 \pm 0,13^{\mathrm{a}}$ & $1,95 \pm 0,05^{\mathrm{a}}$ & $1,82 \pm 0,05^{\mathrm{a}}$ & $1,80 \pm 0,09^{\mathrm{a}}$ \\
$\left(\mathrm{ml} . \mathrm{g}^{-1}\right.$ ) & $0,14 \pm 1,50^{\mathrm{a}}$ & $0,12 \pm 5,50^{\mathrm{b}}$ & $0,12 \pm 1,00^{\mathrm{ab}}$ & $0,11 \pm 2,00^{\mathrm{b}}$ \\
Dureza (kgf) & & & & \\
\hline
\end{tabular}

Média \pm desvio padrão. Letras diferentes em uma mesma linha apresentam diferenças significativas $(\mathrm{p}<0,05)$. 
Segundo os resultados obtidos, foi observada uma diminuição do rendimento dos biscoitos com o aumento da substituição da gordura. $\mathrm{O}$ biscoito padrão apresentou o maior rendimento, seguido por B1 e B2, que não diferiram estatisticamente entre si, e por B3, que apresentou o menor valor. Este comportamento contrasta com aquele observado por Pareyt et al. (2009), que estudaram o impacto dos níveis de açúcar e gordura na estrutura de biscoitos, e observaram que o peso (rendimento) dos mesmos diminuiu linearmente com o aumento da quantidade de gordura na receita. Entretanto, no estudo citado não houve a substituição por outro ingrediente da gordura retirada dos biscoitos. A adição de farinha de casca de pitaia hidratada como substituto da gordura nas formulações B1, B2 e B3, fez com que estas formulações tivessem um aumento gradual da quantidade de água, que se evaporou, durante a cocção, o que explica o maior rendimento de BP em relação aos demais biscoitos.

Os biscoitos BP e B1 apresentaram o maior aumento de diâmetro, não diferindo significativamente entre si, o que sugere que uma substituição de gordura por farinha de casca de pitaia (hidratada) de até $25 \%$ não altera este parâmetro nos biscoitos. Na substituição de gordura em 37,5\% (B2), o aumento de diâmetro foi menor, sendo que B2 e B3 não diferiram significativamente entre si. $\mathrm{O}$ aumento na quantidade de gordura em biscoitos é geralmente associado a uma maior taxa de espalhamento (aumento de diâmetro) durante o assamento, o que provavelmente pode estar relacionado ao aumento da mobilidade do sistema quando a gordura derrete. Altos níveis de gordura aumentam a fase oleosa do sistema, o que aumenta a mobilidade do mesmo e, como consequência, resulta em uma taxa de espalhamento maior durante o assamento (PARYET, 2009).

Hadnadev et al. (2015) investigaram a funcionalidade de emulsões estabilizadas com amido OSA (octenilsuccinato de amido sódico) como substitutos de gordura em cookies e relataram que as emulsões com 50\% e 70\% de óleo (sistema óleo, água e amido) utilizadas também levaram à diminuição do espalhamento (aumento de diâmetro) dos biscoitos. Este efeito correlacionou-se bem com as propriedades reológicas das massas, que também foram estudadas por Hadnadev et al. (2015), que afirmaram que a capacidade do emulsificante amido OSA de absorver água disponível na massa do biscoito e formar uma rede elástica provocou encolhimento elástico após o assamento. Além disso, os pesquisadores relataram que o menor teor de água disponível para o componente de glúten aumentou a rigidez e suprimiu o espalhamento dos biscoitos. Este mesmo efeito pode ter ocorrido nos cookies do presente estudo, visto que a farinha de casca de pitaia tem alta capacidade de absorção de água. 
Entretanto, o comportamento do diâmetro dos biscoitos pode ser variável em cookies com substituição de gordura, e depende do tipo de substituto de gordura utilizado e da quantidade do mesmo. Santiago-Garcia et al. (2017) analisaram a funcionalidade tecnológica de frutanos de Agave angustifólia (Agavinas) como substitutos de gordura em cookies, na proporção de 10, 20 e 30\%. Os autores observaram que o aumento da concentração de agavinas tende a aumentar o diâmetro dos cookies, o que pode ter ocorrido devido à maior solubilidade das agavinas em comparação ao açúcar, que se mantêm dissolvidas por mais tempo durante o assamento, o que poderia também facilitar o fluxo da massa.

Os biscoitos com redução de gordura (B1, B2 e B3) não diferiram significativamente entre si quanto ao aumento de espessura, apresentando valores $35 \%$ mais altos que os valores de BP. O biscoito padrão apresentou o menor aumento de espessura, o que provavelmente foi consequência do seu maior diâmetro, relatado acima, mesmo que este não tenha diferido significativamente em relação a B1. Para Pareyt et al. (2009) e Hadnadev et al. (2015), o aumento do teor de gordura em biscoitos correlacionou-se com o aumento do diâmetro e, como consequência, com a diminuição da espessura destes.

Em relação ao fator de expansão dos biscoitos, pode-se observar pequena influência da substituição de gordura por farinha de casca de pitaia, sendo significativa a diferença somente a partir de 37,5\% de substituição da gordura. Segundo Moretto e Fett (1999), a gordura contribui para a maior expansão do biscoito, o que explica o menor grau de expansão quando níveis maiores de gordura foram substituídos por farinha de casca de pitaia. O índice de expansão dos biscoitos tem sido utilizado para predizer sua qualidade. Aqueles com índice de expansão muito alto ou muito baixo causam problemas na indústria, uma vez que resultam em produtos com tamanho pequeno ou peso muito elevado (GAINES, 1993). Os valores de volume específico, que expressa a relação entre o volume aparente e o peso do biscoito assado, não apresentaram diferença significativa entre si, porque, em geral, ocorreu uma compensação dos valores nas diferentes amostras, sendo que a diminuição do peso em um biscoito foi acompanhada por uma diminuição do seu volume aparente, ou o aumento do peso acompanhado pelo aumento do volume aparente.

Em relação à dureza, observou-se diferença significativa nos biscoitos com substituição de gordura em relação ao biscoito padrão. Os biscoitos com adição de farinha de casca de pitaia apresentaram maior maciez (menor dureza) quando comparados ao padrão. Conforme descrito por Mamat e Hill (2014), as gorduras atuam como um lubrificante durante a mistura dos ingredientes, além de impedirem a formação da rede de glúten na massa. Possivelmente a farinha de casca de pitaia permitiu uma maior fluidez da massa dos cookies 
do que a gordura, levando a uma menor dureza da massa. De forma similar, Giarnetti et al. (2015), ao avaliarem a substituição de $100 \%$ da gordura (manteiga) de cookies por um gel feito com emulsão à base de inulina e azeite extra virgem, observaram uma diminuição significativa na dureza, entretanto, quando 50\% da manteiga foi substituída, não houve diferença significativa na dureza dos cookies em relação ao biscoito controle. Adicionalmente, Rodriguez-Garcia et al. (2013), ao substituírem gradualmente a gordura de biscoitos com quantidades crescentes de inulina, observaram um aumento da dureza com o aumento das quantidades de gordura substituídas, entretanto, no nível mais alto de substituição (40\%), uma diminuição deste parâmetro foi observada. Segundo os autores, o fato ocorreu devido à insuficiência de gordura que, por sua vez, ocasionou uma escassa lubrificação da matriz e o baixo desenvolvimento da estrutura da mesma. Efeito semelhante também pode ter ocorrido pela substituição da manteiga por farinha de casca de pitaia, visto que BP continha $28 \%$ de gordura (base farinha), o que representa uma menor quantidade de gordura comparativamente aos cookies em geral, que fica entre 30 a 45\% (Zoulias et al., 2002; Laguna et al., 2014; Giarnetti et al., 2015). Além disso, a maior umidade da massa nos biscoitos com substituição de gordura, devido à hidratação da farinha, poderia ter contribuído para a menor dureza nos cookies B1, B2 e B3. Estes resultados contrastam com os valores obtidos por Zoulias et al. (2002), que utilizaram substitutos de gordura à base de carboidratos ou proteínas (previamente dissolvidos em água gelada) para substituir até 50\% de gordura em cookies. O efeito do tipo de substituto de gordura e da porcentagem de substituição foi avaliado em relação à textura dos produtos por testes de compressão. A dureza e a fragilidade destes geralmente aumentaram com a substituição de gordura, mas para alguns substitutos, este aumento foi moderado. Laguna et al. (2014) estudaram a textura e as propriedades sensoriais de biscoitos nos quais 15 e $30 \%$ da gordura foi substituída por dois diferentes substitutos de gorduras à base de carboidrato, inulina e solução de hidroxipropilmetilcelulose (HPMC). A substituição de gordura produziu um aumento significativo na dureza e a magnitude do parâmetro dependeu do tipo de substituto de gordura e da sua concentração. A maior substituição de gordura produziu a maior dureza, e os valores mais altos foram atingidos nas substituições por inulina. Entretanto, para 15\% de substituição de gordura por solução de HPMC, não foram encontradas diferenças significativas com o biscoito controle. 
5.5 Análises de Cor da Farinha de Casca de Pitaia e dos Cookies

Os resultados da análise de cor da farinha e das amostras de cookies se encontram na Tabela 5.

Tabela 5 - Resultados das análises de cor da farinha de casca de pitaia do biscoito padrão (BP) e com substituição de $25 \%$ (B1), 37,5\% (B2) e 50\% (B3) da gordura por farinha de casca de pitaia hidratada.

\begin{tabular}{lccccc}
\hline \multirow{2}{*}{ Parâmetros } & \multicolumn{5}{c}{ Resultados } \\
\cline { 2 - 6 } & Farinha & BP & B1 & B2 & B3 \\
\hline L $^{*}$ & $39,41 \pm 0,18$ & $46,21 \pm 0,36^{\mathrm{a}}$ & $39,38 \pm 1,49^{\mathrm{b}}$ & $35,50 \pm 2,07^{\mathrm{b}}$ & $37,04 \pm 1,53^{\mathrm{b}}$ \\
$\mathrm{a}^{*}$ & $7,11 \pm 0,04$ & $2,55 \pm 0,05^{\mathrm{d}}$ & $5,68 \pm 0,38^{\mathrm{c}}$ & $7,00 \pm 0,47^{\mathrm{b}}$ & $8,41 \pm 0,10^{\mathrm{a}}$ \\
$\mathrm{b}^{*}$ & $0,23 \pm 0,05$ & $7,69 \pm 0,12^{\mathrm{a}}$ & $5,62 \pm 0,18^{\mathrm{b}}$ & $4,72 \pm 0,34^{\mathrm{bc}}$ & $3,73 \pm 0,56^{\mathrm{c}}$ \\
\hline
\end{tabular}

Média \pm desvio padrão. Letras diferentes em uma mesma linha apresentam diferenças significativas $(p<0,05)$.

A casca da pitaia possui uma cor vermelho-púrpura que aumenta o interesse no seu valor econômico como ingrediente alimentar. A cor da farinha é um dos atributos mais óbvios da sua qualidade como corante natural. As betalaínas responsáveis pela cor vermelha da pitaia correspondem quase que exclusivamente a betacianinas (TZE et al., 2012). Sengkhamparn et al. (2013) mediu a cor de amostras de casca de pitaia vermelha in natura e em pó, secas em diferentes temperaturas. Para a casca de pitaia in natura, os valores obtidos para $\mathrm{L}^{*}, \mathrm{a}^{*} \mathrm{e} \mathrm{b}^{*}$ foram de $81.89 \pm 0.23,-21.74 \pm 0.31,-0.33 \pm 0.26$, respectivamente. Os valores de $\mathrm{L}^{*}, \mathrm{a}^{*} \mathrm{e}$ $b^{*}$ relatados para a casca de pitaia em pó, seca a uma temperatura de $60^{\circ} \mathrm{C}$, foram de $84.69 \pm$ $0.12,-17.12 \pm 0.13$ e $0.46 \pm 0.17$, respectivamente. Pode-se observar que estes valores de cor para a casca de pitaia em pó se encontram bem diferentes dos valores obtidos no presente estudo, o que pode estar relacionado ao diferente grau de maturação da fruta, ao congelamento da casca antes da secagem, ou ainda a uma degradação de pigmentos pelo contato com a luz e temperatura no processo de secagem. Sendo assim, uma análise de cor da casca in natura antes e depois destes eventos poderia ter sido feita para melhor avaliação dos resultados. 
Figura 2 - Farinha de casca de pitaia vermelha.

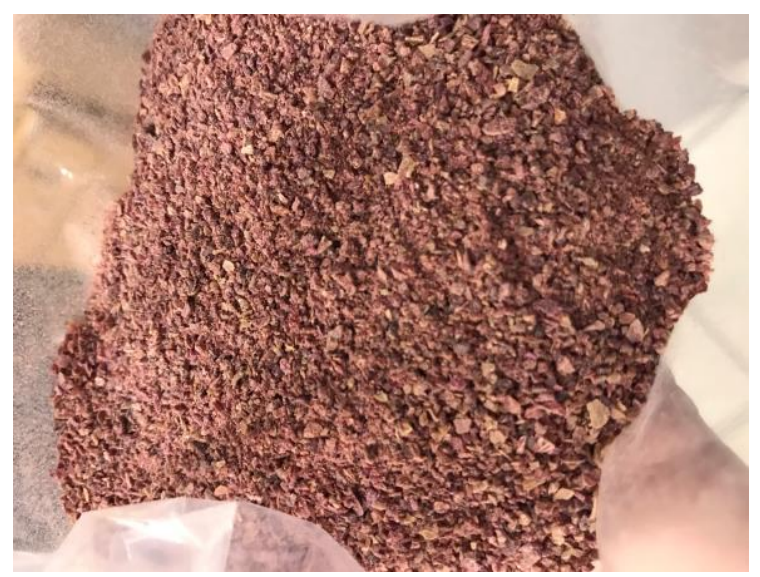

Os biscoitos com substituição de gordura (B1, B2 e B3) não diferiram significativamente entre si em relação à luminosidade $\left(\mathrm{L}^{*}\right)$, porém apresentaram menores valores deste parâmetro quando comparados ao biscoito padrão, sendo estes muito semelhantes aos da farinha de casca de pitaia a partir da substituição em $25 \%$. Isto indica que a adição deste substituto altera a luminosidade dos cookies, diminuindo-a. Este comportamento está de acordo com o esperado ao se observar os valores de luminosidade do substituto, que são mais baixos que os valores do biscoito padrão.

Nos estudos de Hadnadev et al. (2015), as medidas de cor da superfície dos biscoitos também revelaram que os valores de luminosidade $\left(\mathrm{L}^{*}\right)$ diminuíram para todas as amostras reduzidas de gordura, em comparação com a amostra controle, implicando sua cor mais escura. O motivo desse comportamento pode ser o menor teor de gordura que atua como um plastificante que cobre todos os ingredientes em pó (farinha, açúcar, etc.), o que resultou em maior quantidade de açúcar envolvido na reação de Maillard. O fato de os cookies com substituição de gordura não terem apresentado diferença de luminosidade entre si pode estar relacionado à presença do substituto, que tem boa capacidade de ligação com a água, o que, portanto, causou menor disponibilidade desta e, consequentemente, menor mobilidade das espécies participantes das reações de Maillard (HADNADEV et al., 2015).

Os valores de $\mathrm{a}^{*}$ (intensidade da cor vermelha) se mostraram crescentes quanto maior a substituição de gordura nos cookies e todos os valores apresentaram diferença significativa entre si. O biscoito padrão obteve o menor valor e o biscoito B3 o maior valor. O aumento dos parâmetros $\mathrm{a}^{*}$ e diminuição dos parâmetros $\mathrm{L}^{*}$ também são indicadores do progresso do escurecimento (LARA et al., 2011). Além disso, este comportamento era esperado pela adição gradativa de farinha de casca de pitaia como substituto da gordura nas formulações, sendo que esta possui valores maiores do parâmetro $a^{*}$ em relação ao biscoito padrão. 
Consequentemente, observa-se a diminuição dos valores de b* (intensidade da cor amarela), que decresceram com o aumento da adição do substituto. A alteração de cor nos biscoitos pode ser favorável uma vez que o consumidor pode associar a cor à presença de corantes naturais e compostos bioativos benéficos à saúde.

No seguimento das análises dos biscoitos, a composição centesimal, capacidade antioxidante e análise sensorial foram realizadas apenas com o biscoito B1 em comparação ao padrão, devido ao fato deste apresentar uma massa bastante semelhante à padrão, sendo apta a uma linha de produção industrial. Além disso, o biscoito B1 apresentou os melhores resultados em relação ao diâmetro e fator de expansão.

5.6 Composição Centesimal da Farinha e dos Cookies

A Tabela 6 mostra a composição centesimal da farinha de casca de pitaia do presente estudo.

Tabela 6 - Composição centesimal da farinha de casca de pitaia.

\begin{tabular}{lcc}
\hline \multirow{2}{*}{ Parâmetros } & \multicolumn{2}{c}{ Farinha de Casca de Pitaia } \\
\cline { 2 - 3 } & (base úmida) & (base seca) \\
\hline Umidade $(\mathrm{g} / 100 \mathrm{~g})$ & $9,33 \pm 0,09$ & - \\
Cinzas $(\mathrm{g} / 100 \mathrm{~g})$ & $13,32 \pm 0,04$ & $14,69 \pm 0,05$ \\
Proteínas $(\mathrm{g} / 100 \mathrm{~g})$ & $4,47 \pm 0,16$ & $4,92 \pm 0,17$ \\
Lipídios $(\mathrm{g} / 100 \mathrm{~g})$ & $0,44 \pm 0,07$ & $0,48 \pm 0,08$ \\
Fibras Alimentares $(\mathrm{g} / 100 \mathrm{~g})$ & $61,83 \pm 1,43$ & $68,19 \pm 1,58$ \\
Carboidratos $(\mathrm{g} / 100 \mathrm{~g})$ & $10,75 \pm 1,67$ & $11,86 \pm 1,85$ \\
Energia $(\mathrm{kcal} / 100 \mathrm{~g})$ & $64,07 \pm 6,14$ & - \\
\hline
\end{tabular}

A umidade obteve um valor de 9,33\% (g/100g), que estava de acordo com o que preconiza a legislação (ANVISA, 2005), que estabelece umidade máxima 15,0 \% (g/100 g) para farinhas. Os demais resultados estão de acordo com Abreu et al. (2012), que avaliaram a composição química da casca de pitaia vermelha e branca e observaram que estas apresentaram baixo teor de proteínas e lipídios, altos teores de fibra alimentar total, além de baixo valor de energia. 
Em geral, as frutas e suas cascas possuem teores de fibras solúveis maiores do que os farelos de cereais e de leguminosas (JORGE; MONTEIRO, 2005). Em seus estudos sobre a farinha de casca de maracujá, Souza et al. (2008) também observaram um alto teor de fibra alimentar de 66,37 \pm 0,71 g/100g em base úmida $(70,67 \pm 0,71 \mathrm{~g} / 100 \mathrm{~g}$ base seca). Seus valores para cinzas, lipídios, proteínas, carboidratos e valor calórico foram de 8,13 \pm 0,53 $\mathrm{g} / 100 \mathrm{~g}$ base úmida $(8,66 \pm 0,53 \mathrm{~g} / 100 \mathrm{~g}$ base seca), $1,64 \pm 0,08 \mathrm{~g} / 100 \mathrm{~g}$ base úmida $(1,75 \pm$ $0,08 \mathrm{~g} / 100 \mathrm{~g}$ base seca), 11,76 $\pm 1,17 \mathrm{~g} / 100 \mathrm{~g}$ base úmida $(12,52 \pm 1,17 \mathrm{~g} / 100 \mathrm{~g}$ base seca), $72,38 \mathrm{~g} / 100 \mathrm{~g}$ base úmida $(77,07 \mathrm{~g} / 100 \mathrm{~g}$ base seca) e 85,84 kcal/100g, respectivamente.

A Tabela 7 mostra a composição centesimal do biscoito padrão, em comparação com o biscoito com substituição de gordura em 25\% (B1) por farinha de casca de pitaia hidratada.

Tabela 7 - Composição centesimal dos biscoitos padrão (BP) e com substituição de 25\% (B1) da gordura por farinha de casca de pitaia.

\begin{tabular}{lcccc}
\hline \multirow{2}{*}{ Parâmetros } & \multicolumn{2}{c}{ BP } & \multicolumn{2}{c}{ B1 } \\
\cline { 2 - 5 } & (base úmida) & (base seca) & (base úmida) & (base seca) \\
\hline Umidade (g/100g) & $11,71 \pm 0,92^{\mathrm{b}}$ & & $17,13 \pm 0,56^{\mathrm{a}}$ & \\
Cinzas $(\mathrm{g} / 100 \mathrm{~g})$ & $1,33 \pm 0,03^{\mathrm{b}}$ & $1,50 \pm 0,03$ & $1,69 \pm 0,03^{\mathrm{a}}$ & $2,04 \pm 0,04$ \\
Proteínas (g/100g) & $6,39 \pm 0,01^{\mathrm{a}}$ & $7,24 \pm 0,01$ & $6,27 \pm 0,16^{\mathrm{a}}$ & $7,57 \pm 0,19$ \\
Lipídios (g/100g) & $8,35 \pm 0,01^{\mathrm{a}}$ & $9,45 \pm 0,01$ & $6,33 \pm 0,18^{\mathrm{b}}$ & $7,63 \pm 0,22$ \\
Fibras Alimentares & $4,42 \pm 0,19^{\mathrm{b}}$ & $5,00 \pm 0,21$ & $7,94 \pm 0,45^{\mathrm{a}}$ & $9,59 \pm 0,55$ \\
(g/100g) & & & & \\
Carboidratos (g/100g) & $68,49 \pm 0,44^{\mathrm{a}}$ & $77,57 \pm 0,50$ & $60,11 \pm 0,70^{\mathrm{a}}$ & $72,54 \pm 0,85$ \\
Energia (kcal/100g) & $374,63 \pm 1,70^{\mathrm{a}}$ & & $323,47 \pm 3,28^{\mathrm{b}}$ &
\end{tabular}

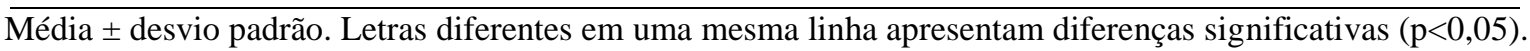

Não foram observadas diferenças significativas entre as amostras para os valores de proteínas e carboidratos. O biscoito B1 apresentou maiores valores de umidade, cinzas e fibras alimentares totais em relação ao biscoito BP. A umidade do biscoito padrão demonstrou valor de acordo com o que preconiza a legislação (ANVISA, 1978), que estabelece umidade máxima 14,0 \% (g/100 g) para biscoitos e bolachas, enquanto que a umidade do biscoito B1 obteve um valor acima deste limite. Este fato pode estar relacionado ao uso de farinha de casca de pitaia hidratada para a substituição da gordura, o que aumentou a umidade da massa, não sendo o tempo de forneamento aplicado a estes cookies suficiente para a evaporação ideal da mesma. 
O aumento significativo (aproximadamente 27\%) no teor de cinzas pode ser explicado pelo fato de a farinha possuir um valor relativamente alto deste componente, o que sugere elevado conteúdo de minerais presentes. Da mesma forma, o valor de fibras alimentares totais apresentou um aumento de aproximadamente $79 \%$ em relação ao biscoito padrão. De acordo com a legislação brasileira, este produto poderia utilizar o apelo de "fonte de fibras alimentares" (mínimo de 3 g fibras/100 g, em sólidos) ou "alto teor de fibras alimentares" (mínimo de 6 g fibras/100 g, em sólidos) em sua embalagem, no caso de comercialização (ANVISA, 1998). As fibras alimentares formam um conjunto de substâncias derivadas de vegetais resistentes à ação das enzimas digestivas humanas e suas propriedades físicoquímicas produzem diferentes efeitos fisiológicos no organismo. Estas regularizam o funcionamento intestinal, o que as tornam relevantes para o bem-estar das pessoas saudáveis e para o tratamento dietético de várias patologias (SCHWEIZER; EDWARDS, 2013).

Como esperado, o biscoito B1 apresentou menores valores de lipídios em relação ao biscoito padrão, com redução deste componente em aproximadamente $31 \%$. Consequentemente, o biscoito com substituição de gordura apresentou menor valor calórico em relação ao biscoito padrão. De acordo com a legislação brasileira, os cookies com redução de gordura podem ser rotulados como "light" ou "reduzido em calorias" em comparação com os cookies de controle (ANVISA, 1998). A ingestão de alimentos com alto teor de energia está relacionada aos incrementos no peso corporal e na obesidade, portanto os produtos alimentares reduzidos em gordura são adequados para reduzir o risco de incidência de doenças crônicas (SANTIAGO-GARCÍA et al., 2017).

O valor calórico dos cookies seria superior no caso da adição das gotas de chocolate meio amargo na formulação. O ingrediente utilizado na produção dos cookies para a análise sensorial possui um valor calórico aproximado de $544 \mathrm{kcal} / 100 \mathrm{~g}$.

\subsubsection{Atividade Antioxidante da Farinha de Casca de Pitaia e dos Cookies}

Os resultados da análise de atividade antioxidante pelo método ABTS de eliminação de radicais estão apresentados na Tabela 8 . 
Tabela 8 - Atividade antioxidante ao trolox das amostras de farinha de casca de pitaia e dos biscoitos padrão (BP) e com substituição de $25 \%$ (B1) da gordura por farinha de casca de pitaia hidratada.

\begin{tabular}{lcc}
\hline Amostra & $\begin{array}{c}\text { Atividade Antioxidante } \\
(\boldsymbol{\mu M} \text { Trolox/g amostra) } \\
(\mathbf{b a s e} \text { úmida) }\end{array}$ & $\begin{array}{c}\text { Atividade Antioxidante } \\
(\boldsymbol{\mu M} \text { Trolox/g amostra) } \\
(\mathbf{b a s e} \text { seca) }\end{array}$ \\
\hline Farinha de Casca de Pitaia & $18,14 \pm 5,06$ & $20,01 \pm 5,06$ \\
\hline BP & $1,08 \pm 0,19^{\mathrm{b}}$ & $1,22 \pm 0,19^{\mathrm{b}}$ \\
B1 & $2,1 \pm 0,61^{\mathrm{a}}$ & $2,59 \pm 0,61^{\mathrm{a}}$ \\
\hline Média \pm desvio padrão. Letras diferentes em uma mesma coluna apresentam diferenças significativas $(\mathrm{p}<0,05)$.
\end{tabular}

Pode-se observar que a adição de farinha de casca de pitaia ao biscoito B1 aumentou significativamente a capacidade antioxidante deste em relação ao padrão, devido ao teor elevado de compostos bioativos presentes na farinha casca de pitaia.

Vaillant et al. (2005) estudaram as propriedades antioxidantes de três cultivares de pitaia vermelho-púrpura (Hylocereus sp.). A capacidade antioxidante de cada amostra foi medida pelo método de capacidade de absorção de radical de oxigênio (ORAC) e os resultados foram expressos em $\mu$ mol Trolox / $\mathrm{g}$ de extrato da fruta. As capacidades antioxidantes totais dos sucos preparados a partir dos três cultivares de pitaia variaram de $(8,8$ a 11,3) $\mu \mathrm{mol}$ Trolox / g de polpa fresca sem sementes. Estes valores são quase o dobro do medido pelo mesmo método para suco comercial de maçã e suco de uva branca e são da mesma magnitude que a beterraba e o morango. Descobertas recentes classificam a beterraba entre os 10 vegetais mais antioxidantes, o que significa que o suco de pitaia vermelha pode ser considerada como um potente antioxidante (VAILLANT et al., 2005). A farinha de casca de pitaia apresentou valores de atividade antioxidante ainda mais elevados do que os do suco da fruta.

Prado (2009) avaliou a atividade antioxidante de polpas liofilizadas de frutas tropicais e analisou as suas atividades antioxidantes através do método ABTS. Os resultados obtidos para abacaxi, acerola, manga, maracujá, melão, goiaba e pitanga, em $\mu$ mol Trolox / g de polpa, estão listados na Tabela 9. A farinha de casca de pitaia apresentou capacidade antioxidante maior que a polpa de abacaxi e manga, e menor que a polpa de maracujá. 
Tabela 9 - Atividade antioxidante de polpas liofilizadas tropicais por método ABTS.

\begin{tabular}{lcc}
\hline Amostra & $\begin{array}{c}\text { Atividade Antioxidante } \\
(\boldsymbol{\mu M} \text { Trolox/g amostra) } \\
(\mathbf{b a s e} \text { úmida) }\end{array}$ & $\begin{array}{c}\text { Atividade Antioxidante } \\
(\boldsymbol{\mu M} \text { Trolox/g amostra) } \\
(\mathbf{b a s e} \text { seca) }\end{array}$ \\
\hline Abacaxi & $2,62 \pm 0,03$ & $18,7 \pm 0,2$ \\
Acerola & $39 \pm 3$ & $788 \pm 55$ \\
Manga & $2,7 \pm 0,1$ & $18,7 \pm 0,8$ \\
Maracujá & $3,34 \pm 0,08$ & $25 \pm 1$ \\
Melão & $0,46 \pm 0,04$ & $6,7 \pm 0,7$ \\
Goiaba & $5,14 \pm 0,06$ & $46 \pm 1$ \\
Pitanga & $6,3 \pm 0,1$ & $82 \pm 2$ \\
\hline
\end{tabular}

Fonte: Adaptado de Prado, 2009.

É válido salientar que, devido à complexa reatividade dos fitoquímicos, as atividades antioxidantes de alimentos e extratos alimentares não devem ser avaliadas por um único método e pelo menos dois tipos de teste são recomendados para a determinação da atividade antioxidante para estabelecer autenticidade (SCHLESIER et al., 2002).

\subsubsection{Análise Sensorial dos Cookies}

Na Tabela 10 podem-se observar os resultados das avaliações de aparência, cor, odor, textura, sabor, sabor residual e aceitação global do biscoito padrão em relação ao biscoito com redução de gordura em $25 \%$ (B1). 
Tabela 10 - Atributos sensoriais dos biscoitos padrão (BP) e com substituição de $25 \%$ (B1) da gordura por farinha de casca de pitaia hidratada e aceitabilidade.

\begin{tabular}{|c|c|c|c|c|}
\hline \multirow{2}{*}{$\begin{array}{l}\text { Atributos } \\
\text { Sensoriais }\end{array}$} & \multicolumn{2}{|c|}{ Notas } & \multicolumn{2}{|c|}{ Aceitabilidade (\%) } \\
\hline & BP & B1 & BP & B1 \\
\hline Aparência & $7,42 \pm 0,92^{\mathrm{a}}$ & $7,04 \pm 1,12^{b}$ & 82 & 78 \\
\hline Cor & $7,36 \pm 0,87^{\mathrm{a}}$ & $7,32 \pm 1,12^{\mathrm{a}}$ & 82 & 81 \\
\hline Odor & $7,26 \pm 1,07^{\mathrm{a}}$ & $7,32 \pm 1,07^{\mathrm{a}}$ & 81 & 81 \\
\hline Textura & $7,12 \pm 1,32^{\mathrm{a}}$ & $6,84 \pm 1,42^{a}$ & 79 & 76 \\
\hline Sabor & $7,54 \pm 1,15^{\mathrm{a}}$ & $7,56 \pm 1,15^{\mathrm{a}}$ & 84 & 84 \\
\hline Sabor Residual & $7,38 \pm 1,10^{\mathrm{a}}$ & $7,14 \pm 1,20^{a}$ & 82 & 79 \\
\hline Aceitação Global & $7,54 \pm 0,87^{\mathrm{a}}$ & $7,36 \pm 1,12^{\mathrm{a}}$ & 84 & 82 \\
\hline
\end{tabular}

Média \pm desvio padrão. Letras diferentes em uma mesma linha apresentam diferenças significativas $(p<0,05)$.

De acordo com os resultados da análise sensorial, observou-se que os biscoitos apresentaram diferença significativa apenas no atributo de aparência, na qual o biscoito padrão obteve a maior nota. Isto pode ter ocorrido devido ao fato de os biscoitos com substituição de gordura apresentarem coloração rosa, o que pode ter interferido na aprovação dos provadores, já que difere da cor dos cookies tradicionais. Esta diferença, entretanto, não afetou a aceitação global, que não diferiu significantemente entre as amostras. Os demais atributos não apresentaram diferenças significativas entre os cookies. De forma geral, a média de aceitação dos avaliadores para os atributos, na escala hedônica, foi entre "gostei moderadamente" e "gostei muito".

Seis dos avaliadores fizeram comentários na ficha de avaliação sobre a textura dos biscoitos, dizendo que esta poderia ser mais crocante, enquanto outro avaliador comentou que a aparência do biscoito B1 lembrava um produto integral, o que o agradava bastante. As críticas em relação à textura podem estar relacionadas ao maior teor de umidade dos cookies, especialmente daqueles com substituição de gordura por farinha de casca de pitaia hidratada. O presente estudo visou avaliar biscoitos do tipo macio, entretanto esta característica chamou a atenção de alguns consumidores, visto que estes estão acostumados aos produtos comerciais disponíveis, que são mais secos e mais assados. Mesmo assim, os cookies tiveram boa aceitação global e apresentaram índices de aceitabilidade superiores a 70\%.

Trabalhos anteriores também obtiveram pontuações aceitáveis para biscoitos com baixo teor de gordura. Em seus estudos de substituição de gordura em cookies por emulsões contendo 50 e $70 \%$ de óleo, Hadnadev et al. (2015) observou que todos os cookies foram 
sensorialmente aceitos, e os de controle obtiveram as pontuações mais altas, enquanto o aumento na redução da gordura induziu a diminuição na aceitação geral dos cookies. No entanto, a distribuição da resposta (desvios padrão) sugeriu que os cookies com a maior redução de gordura expressavam uma maior amplitude de pontuação em comparação com o controle. Isso pode estar relacionado a diferentes preferências sensoriais dos avaliadores para este tipo de produtos. Adicionalmente, Laguna et al. (2014) estudaram as propriedades sensoriais de biscoitos nos quais 15 e $30 \%$ da gordura foi substituída por dois diferentes substitutos de gorduras à base de carboidrato e o estudo do consumidor revelou que a substituição de gordura em até $15 \%$ forneceu biscoitos aceitáveis (índices de aceitabilidade de 61 a 66\%), mas uma substituição mais alta diminuiu a aceitação global (índice de aceitabilidade de 52\%). Santiago-Garcia et al. (2017) reduziram o teor de gordura em 10, 20 e $30 \%$ em cookies e os dados sensoriais relataram semelhanças nas características de qualidade dos cookies contendo substituição em até $20 \%$ em relação aos cookies de controle.

Esses resultados provavelmente indicam que as formulações de biscoito são muito variáveis (diferentes tipos de gordura, quantidades de farinha ou substituintes de gordura), de modo que cada formulação possui suas próprias características e expectativas dos consumidores.

Em relação à intenção de compra (Figura 3), 58\% dos avaliadores afirmaram que comprariam o biscoito BP enquanto $54 \%$ afirmaram que comprariam o biscoito B1, sendo que $34 \%$ dos avaliadores afirmaram que comprariam os dois biscoitos. Portanto, evidenciou-se que mais da metade dos avaliadores comprariam o biscoito com redução de gordura caso este estivesse comercialmente disponível. 
Figura 3 - Intenção de compra dos avaliadores em relação aos biscoitos padrão (BP) e com substituição de $25 \%$ (B1) da gordura por farinha de casca de pitaia hidratada.

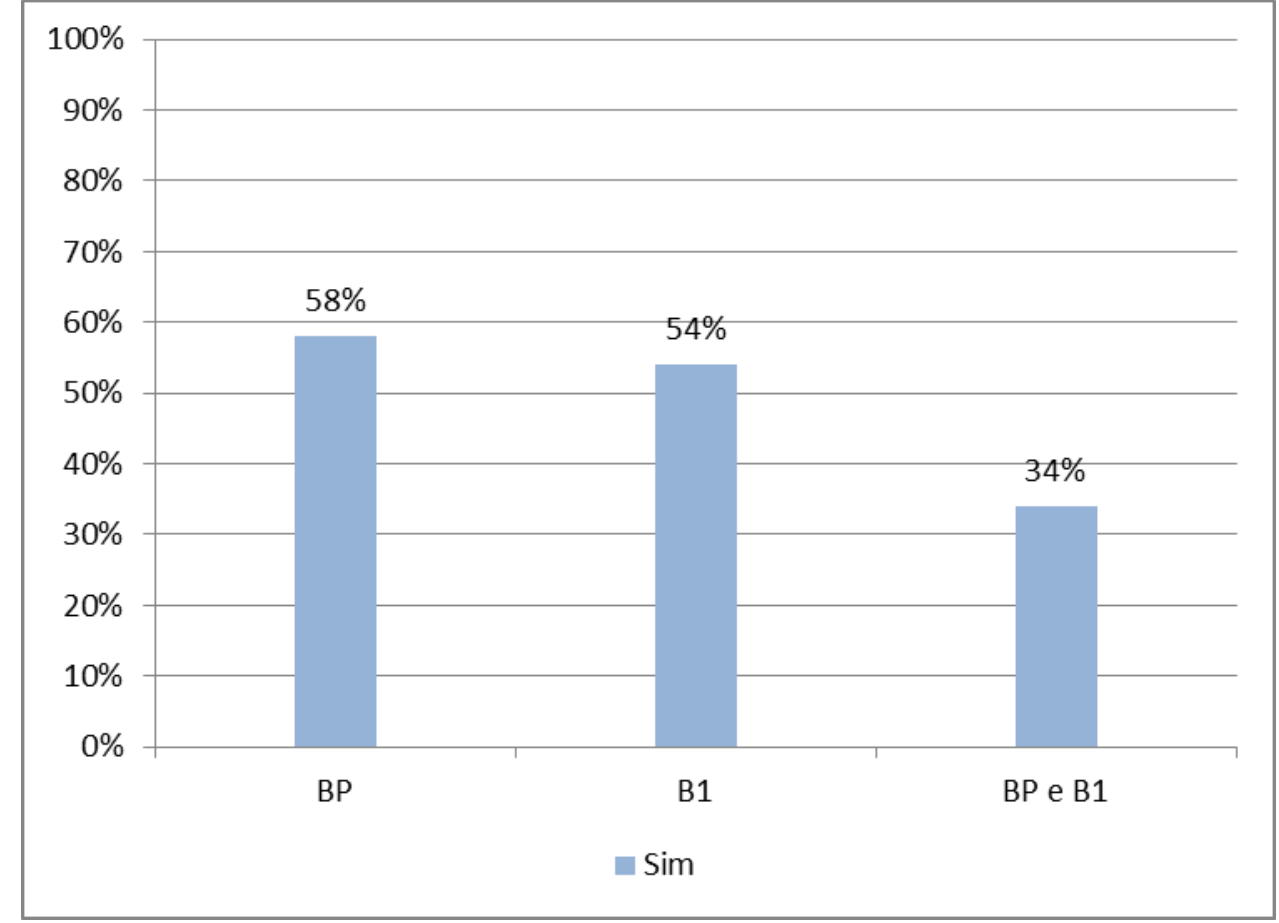




\section{CONCLUSÃO}

Com base nos resultados deste estudo, pode-se concluir que existe o potencial para a utilização da farinha de casca de pitaia no enriquecimento de produtos, como biscoitos, como uma alternativa para reduzir o teor de gordura destes alimentos, aumentar sua capacidade antioxidante e melhorar seu valor nutritivo. Uma substituição da gordura em até $25 \%$ manteve a maior parte das propriedades estruturais e sensoriais dos cookies, além de proporcionar a elaboração de cookies "light" com alto teor de fibras. A utilização da casca de pitaia para este fim contribui também para a redução do desperdício de subprodutos da indústria alimentícia. 


\section{REFERÊNCIAS}

ABREU, W. C. et al. Physicochemical characteristics and total antioxidant activity of red and white pitaya. Revista do Instituto Adolfo Lutz (Impresso), v. 71, n. 4, p. 656-661, 2012.

AMERICAN ASSOCIATION OF CEREAL CHEMISTS - AACC. Approved methods of the American Association of Cereal Chemists. 9. Ed. Saint Paul: AACC, 1995. v. 2.

AMID, M; MANAP, M. Y. A. Purification and characterisation of a novel amylase enzyme from red pitaya (Hylocereus polyrhizus) peel. Food chemistry, v. 165, p. 412-418, 2014.

BAKAR, J. et al. Spray-drying optimization for red pitaya peel (Hylocereus polyrhizus). Food and Bioprocess Technology, v. 6, n. 5, p. 1332-1342, 2013.

BALTSAVIAS, A.; JURGENS, A.; VAN VLIET, T. Fracture properties of short-dough biscuits: effect of composition. Journal of Cereal Science, v. 29, n. 3, p. 235-244, 1999.

BRASIL, ANVISA. Agência Nacional da Vigilância Sanitária. Resolução-CNNPA no ${ }^{\text {12, de }}$ 1978. Diário Oficial da União.

BRASIL. Ministério da Saúde. ANVISA. Resolução RDC n. 263, de 22 de setembro de 2005. Regulamento técnico para produtos de cereais, amidos, farinhas e farelos. Diário Oficial da República Federativa do Brasil, Brasília, DF, 23 set. 2005. Seção 1, p.368-369.

BRASIL. Ministério da Saúde. Secretaria de Vigilância Sanitária. Portaria SVS no 27 de 13 de janeiro de 1998. Regulamento técnico referente à informação nutricional complementar. Disponível em: . Acesso em

BRASIL. http://www.brasil.gov.br/saude/2017/04/obesidade-cresce-60-em-dez-anos-nobrasil <acesso em: $05 \mathrm{dez} 2017$ >

BATH, D. E.; SHELKE, K.; HOSENEY, R. C. Fat replacers in high-ratio layer cakes. Cereal foods world (USA), 1992.

BOBBIO, FO BOBBIO. PA Introdução a química de alimentos, 2. São Paulo, 1995.

DE GRAAF, C. E. E. S. et al. Nonabsorbable fat (sucrose polyester) and the regulation of energy intake and body weight. American Journal of Physiology-Regulatory, Integrative and Comparative Physiology, v. 270, n. 6, p. R1386-R1393, 1996.

DE MORAES, K. S. et al. Avaliação tecnológica de biscoitos tipo cookie com variações nos teores de lipídio e de açúcar. Ciênc. Tecnol. Aliment, v. 30, n. Supl 1, p. 233-242, 2010.

DONADIO, L. C. Pitaya. Rev. Bras. Frutic., Jaboticabal, v. 31, n. 3, Sept. 2009. Available from <http://www.scielo.br/scielo.php?script=sci_arttext\&pid=S010029452009000300001\&lng=en\&nrm=iso $>$ access on $10 \quad$ Oct. 2017. http://dx.doi.org/10.1590/S0100-29452009000300001. 
European Food Safety Agency. Scientific opinion on dietary reference values for fats, including saturated fatty acids, polyunsaturated fatty acids, monounsaturated fatty acids, trans fatty acids, and cholesterol. European Food Safety Agency Journal, 8 (2010), pp. $1461-1568$

FERNÁNDEZ-LÓPEZ, J. et al. Storage stability of a high dietary fibre powder from orange by-products. International journal of food science \& technology, v. 44, n. 4, p. 748-756, 2009.

FOLTZ, J. L. et al. Population-level intervention strategies and examples for obesity prevention in children. Annual review of nutrition, v. 32, p. 391-415, 2012.

GAINES, C. S. Collaborative studies on the baking quality of cookie flour by wire-cut type formulations (AACC methods 10-53 and 10-54). Cereal foods world, v. 38, n. 1, p. 26-30, 1993.

GIARNETTI, M. et al. Fat replacement in shortbread cookies using an emulsion filled gel based on inulin and extra virgin olive oil. LWT-Food Science and Technology, v. 63, n. 1, p. 339-345, 2015.

GHOTRA, B. S.; DYAL, S. D.; NARINE, S. S. Lipid shortenings: a review. Food Research International, v. 35, n. 10, p. 1015-1048, 2002.

GIUNTINI, E. B.; LAJOLO, F. M.; DE MENEZES, E. W. Potencial de fibra alimentar em países ibero-americanos: alimentos, produtos e resíduos. Archivos latinoamericanos de nutrición, v. 53, n. 1, p. 14-20, 2003.

HADNAĐEV, T. D. et al. Functionality of OSA starch stabilized emulsions as fat replacers in cookies. Journal of Food Engineering, v. 167, p. 133-138, 2015.

HALLIWELL, B.; GUTTERIDGE, J.M.C. Free radicals in biology and medicine. Oxford University Press, USA, 2015.

HAQUE, Z. U.; JI, T. Cheddar whey processing and source: II. Effect on non-fat ice cream and yoghurt. International journal of food science \& technology, v. 38, n. 4, p. 463-473, 2003.

HORWITZ, W.; LATIMER, G. W. AOAC International. Official methods of analysis of AOAC International. 18th ed. Gaithersburg, MD: AOAC International, 2005.

HOSENEY, R. C. et al. Principles of cereal science and technology. American Association of Cereal Chemists (AACC), 1994.

INSTITUTO ADOLFO LUTZ. Métodos físico-químicos para análise de alimentos. Coordenadores Odair Zenebon, Neus Sadocco Pascuet e Paulo Tiglea. São Paulo: Instituto Adolfo Lutz, 2008 p. 1020. Edição Digital. Disponível em: <http://www.crq4.org.br/sms/files/file/analisedealimentosial_2008.pdf >. Acesso em: 11 out. 2017. 
JAMILAH, B. et al. Physico-chemical characteristics of red pitaya (Hylocereus polyrhizus) peel. International Food Research Journal, v. 18, n. 1, 2011.

JORGE, J. S.; MONTEIRO, J. B. R. O efeito das fibras alimentares na ingestão, digestão e absorção dos nutrientes. Nutrição Brasil, v. 4, n. 4, p. 218-229, 2005.

LAGUNA, L. et al. HPMC and inulin as fat replacers in biscuits: Sensory and instrumental evaluation. LWT-Food Science and Technology, v. 56, n. 2, p. 494-501, 2014.

LANEUVILlE, S. I.; PAQUIN, P.; TURGEON, S. L. Formula Optimization of a Low-fat Food System Containing Whey Protein Isolate-Xanthan Gum Complexes as Fat Replacer. Journal of food science, v. 70, n. 8, 2005.

LARA, E. et al. Structural and physical modifications of corn biscuits during baking process. LWT-Food Science and Technology, v. 44, n. 3, p. 622-630, 2011.

LUCCA, P. A.; TEPPER, B. J. Fat replacers and the functionality of fat in foods. Trends in Food Science \& Technology, v. 5, n. 1, p. 12-19, 1994.

LUDERS, L.; MCMAHON, G. The pitaya or dragon fruit. Department of Primary Industries \& Fisheries. Northern Territory, Australia, Agnote D, v. 42, 2006.

MAACHE-REZZOUG, Z. et al. Effect of principal ingredients on rheological behaviour of biscuit dough and on quality of biscuits. Journal of Food Engineering, v. 35, n. 1, p. 23-42, 1998.

MAMAT, H.; HILL, S. E. Effect of fat types on the structural and textural properties of dough and semi-sweet biscuit. Journal of food science and technology, v. 51, n. 9, p. 19982005, 2014.

MANACH, C. et al. Polyphenols: food sources and bioavailability. The American journal of clinical nutrition, v. 79, n. 5, p. 727-747, 2004.

MANLEY, D. Biscuit, cracker and cookie recipes for the food industry. Elsevier, 2001.

MANLEY, D. Technology of biscuits, crackers and cookies, (2nd ed.), Woodhead Publishing Company, Cambridge, England (1996).

MATTES, R. D. Position of the American Dietetic Association: fat replacers. 1998.

MATZ, S.A. 1992. Cookie and Cracker Technology, 3rd ed. Westport, CT: AVI Publishing. WYBRANIEC, Sławomir; MIZRAHI, Yosef. Fruit flesh betacyanin pigments in Hylocereus cacti. Journal of Agricultural and Food Chemistry, v. 50, n. 21, p. 6086-6089, 2002.

MCEWAN, J. A.; SHARP, T. M. Technical, economic and consumer barriers to the consumption of reduced fat bakery products. Nutrition \& Food Science, v. 30, n. 1, p. 16-18, 2000 .

MEILGAARD, M.; CIVILLE, G. V.; CARR, B. T. Overall difference tests: does a sensory difference exist between samples. Sensory evaluation techniques, v. 4, p. 63-104, 2007. 
MELLO, F. R. de et al . Antioxidant properties, quantification and stability of betalains from pitaya (Hylocereus undatus) peel. Cienc. Rural, Santa Maria, v. 45, n. 2, p. 323-328, Feb. 2015 . Available from <http://www.scielo.br/scielo.php?script=sci_arttext\&pid=S010384782015000200323\&lng=en\&nrm=iso >. access on 10 Oct. 2017. Epub Oct 21, 2014. http://dx.doi.org/10.1590/0103-8478cr20140548.

MIZRAHI, Y. et al. Cacti as crops. Hort. Rev, v. 18, p. 291-319, 1997.

MORENO, L. A. et al. Trends of dietary habits in adolescents. Critical reviews in food science and nutrition, v. 50, n. 2, p. 106-112, 2010.

MORETTO, E.; FETT, R. Processamento e análise de biscoitos. Livraria Varela, 1999.

NUNES, E. N. et al. Pitaia (Hylocereus sp.): Uma revisão para o Brasil. Gaia Scientia, v. 8, n. $1,2014$.

O'SHEA, N.; ARENDT, E. K.; GALLAGHER, E. Dietary fibre and phytochemical characteristics of fruit and vegetable by-products and their recent applications as novel ingredients in food products. Innovative Food Science \& Emerging Technologies, v. 16, p. $1-10,2012$.

PALZER, S. Food structures for nutrition, health and wellness. Trends in Food Science \& Technology, v. 20, n. 5, p. 194-200, 2009.

PAREYT, B.; DELCOUR, J. A. The role of wheat flour constituents, sugar, and fat in low moisture cereal based products: a review on sugar-snap cookies. Critical reviews in food science and nutrition, v. 48, n. 9, p. 824-839, 2008.

PAREYT, B. et al. The role of sugar and fat in sugar-snap cookies: Structural and textural properties. Journal of Food Engineering, v. 90, n. 3, p. 400-408, 2009.

PRADO, A. Composição fenólica e atividade antioxidante de frutas tropicais. 2009. Tese de Doutorado. Universidade de São Paulo.

RE, R. et al. Antioxidant activity applying an improved ABTS radical cation decolorization assay. Free radical biology and medicine, v. 26, n. 9, p. 1231-1237, 1999.

RODRÍGUEZ-GARCÍA, J. et al. Effect of fat replacement by inulin on textural and structural properties of short dough biscuits. Food and Bioprocess Technology, v. 6, n. 10, p. 2739$2750,2013$.

RUFINO, M. S. M. et al. Determinação da atividade antioxidante totalem frutas pela captura do radical livre ABTS. Fortaleza: Embrapa Agroindústria Tropical, 2007b. 4p.(Embrapa Agroindústria Tropical. Comunicado Técnico, 128).

SCHLESIER, K. et al. Assessment of antioxidant activity by using different in vitro methods. Free radical research, v. 36, n. 2, p. 177-187, 2002. 
SCHWEIZER, T. F.; EDWARDS, C. A. (Ed.). Dietary Fibre-A Component of Food: Nutritional Function in Health and Disease. Springer Science \& Business Media, 2013.

SERNA-SALDIVAR, S. O. Cereal grains: laboratory reference and procedures manual. CRC Press, 2012.

SENGKHAMPARN, N. et al. Effects of blanching and drying on fiber rich powder from pitaya (Hylocereus undatus) peel. International Food Research Journal, v. 20, n. 4, 2013.

SOUZA, M. W.S.; FERREIRA, T. B.O.; VIEIRA, I. F.R. Composição centesimal e propriedades funcionais tecnológicas da farinha da casca do maracujá. Alimentos e Nutrição Araraquara, v. 19, n. 1, p. 33-36, 2008.

TZE, N. L. et al. Physicochemical and nutritional properties of spray-dried pitaya fruit powder as natural colorant. Food Science and Biotechnology, v. 21, n. 3, p. 675-682, 2012.

VAILLANT, F. et al. Colorant and antioxidant properties of red-purple pitahaya (Hylocereus sp.). Fruits, v. 60, n. 1, p. 3-12, 2005.

WARD, F. M. Hydrocolloid systems as fat mimetics in bakery products: icings, glazes and fillings. Cereal foods world (USA), 1997.

WESTSTRATE, J. A.; VAN HET HOF, K. H. Sucrose polyester and plasma carotenoid concentrations in healthy subjects. The American journal of clinical nutrition, v. 62, n. 3, p. 591-597, 1995.

WU, L. et al. Antioxidant and antiproliferative activities of red pitaya. Food Chemistry, v. 95, n. 2, p. 319-327, 2006.

ZAHN, S.; PEPKE, F.; ROHM, H. Effect of inulin as a fat replacer on texture and sensory properties of muffins. International journal of food science \& technology, v. 45, n. 12, p. 2531-2537, 2010.

ZOULIAS, E. I.; OREOPOULOU, V.; KOUNALAKI, E. Effect of fat and sugar replacement on cookie properties. Journal of the Science of Food and Agriculture, v. 82, n. 14, p. 1637 1644, 2002.

ZOULIAS, E. I.; OREOPOULOU, V.; TZIA, C. Textural properties of low-fat cookies containing carbohydrate-or protein-based fat replacers. Journal of Food Engineering, v. 55, n. 4, p. 337-342, 2002.

ZOULIAS, E. I.; PIKNIS, S.; OREOPOULOU, V. Effect of sugar replacement by polyols and acesulfame $\mathrm{K}$ on properties of low fat cookies. Journal of the Science of Food and Agriculture, v. 80, n. 14, p. 2049-2056, 2000. 


\section{ANEXO A - Ficha UTILIZAda PARA ANÁlise SENSORIAl dos COOKIES.}

\section{ANÁLISE SENSORIAL DE COOKIES}

Nome: Idade: Data:

\section{PROCEDIMENTOS}

Você está recebendo duas amostras de cookies codificados. Avalie as características de aparências, cor, odor, textura, sabor, sabor residual e aceitação global das amostras e atribua notas para aceitação de cada atributo, segundo a tabela abaixo:

\begin{tabular}{|l|l|}
\hline \multicolumn{2}{|c|}{ Aceitação } \\
\hline 1 & Desgostei muitíssimo \\
\hline 2 & Desgostei muito \\
\hline 3 & Desgostei moderadamente \\
\hline 4 & Desgostei ligeiramente \\
\hline 5 & Nem gostei nem desgostei \\
\hline 6 & Gostei ligeiramente \\
\hline 7 & Gostei moderadamente \\
\hline 8 & Gostei muito \\
\hline 9 & Gostei muitíssimo \\
\hline
\end{tabular}

Anotar para cada característica e cada amostra o resultado na tabela abaixo. Proceder avaliando primeiro a aparência, cor e odor. Através de degustação, avaliar textura, sabor, sabor residual e aceitação global. Tome água entre as amostras.

\begin{tabular}{|l|l|l|}
\hline & AMOSTRA 896 & AMOSTRA 748 \\
\hline Aparência & & \\
\hline Cor & & \\
\hline Odor & & \\
\hline Textura & & \\
\hline Sabor & & \\
\hline Sabor Residual & & \\
\hline Aceitação Global & & \\
\hline
\end{tabular}

Comentários:

Você compraria este produto? ( ) Sim ( ) Não. Qual? 